\title{
Entre tentativas reglamentarias y sirvientes organizados: la regulación municipal del servicio doméstico. Ciudad de Buenos Aires, 1875-1912
}

Regulatory Attempts and Organized Servants: Municipal Regulation of Domestic Service in the City of Buenos Aires, 1875-1912

Entre tentatives réglementaires et domestiques organisés : la régulation municipale du service domestique. Ville de Buenos Aires, 1875-1912

\section{Cecilia L. Allemandi}

\section{(2) OpenEdition}

\section{Edición electrónica}

URL: http://journals.openedition.org/rhj/556

DOI: $10.4000 /$ rhj.556

ISSN: 0719-4153

Editor

ACTO Editores Ltda

Referencia electrónica

Cecilia L. Allemandi, « Entre tentativas reglamentarias y sirvientes organizados: la regulación

municipal del servicio doméstico. Ciudad de Buenos Aires, 1875-1912 », Revista Historia y Justicia [En línea], 6 | 2016, Publicado el 30 abril 2016, consultado el 06 mayo 2019. URL : http:// journals.openedition.org/rhj/556 ; DOI : 10.4000/rhj.556 


\title{
ENTRE TENTATIVAS REGLAMENTARIAS Y SIRVIENTES ORGANIZADOS: LA REGULACIÓN MUNICIPAL DEL SERVICIO DOMÉSTICO. CiUdAd DE BuENOS AIRES, 1875-1912
}

\author{
Cecilia L. ALLEMANDI $(*)$
}

\begin{abstract}
Este artículo analiza una serie de intentos de regulación municipal del servicio doméstico en la ciudad de Buenos Aires a fines del siglo XIX y principios del XX. Como correlato de estos procesos, reconstruye una serie de experiencias organizativas de los y las trabajadoras del sector que permiten comprender mejor esos marcos regulatorios. Procura demostrar que la regulación del servicio doméstico respondió a un universo de problemas, asociados al crecimiento y las transformaciones de la ciudad. Trabaja con ordenanzas y reglamentos publicados en los digestos municipales, proyectos presentados y tratados en las sesiones ordinarias del Consejo Deliberante, prensa obrera y magazines ilustrados, entre otros documentos de época.
\end{abstract}

Palabras Clave: Buenos Aires, 1875-1912, regulaciones municipales, servicio doméstico, conflicto social

\section{Regulatory Attempts and Organized Servants: Municipal Regulation of Domestic Service in the City of Buenos Aires, 1875-1912}

This article analyses a series of attempted municipal regulations of domestic work in the City of Buenos Aires in the late nineteenth and early twentieth centuries. In parallel to these processes, this study reconstructs the organizing experiences of domestic workers, which shade light on those regulatory frameworks. The article shows that domestic service regulation responded to a broad range of issues associated with the growth and transformation of the city.

It examines laws and regulations published in municipal law digests, projects presented at the regular meetings of the City Council of Buenos Aires, workers' press, and illustrated magazines, among others documents from the period.

Keywords: City of Buenos Aires, 1875-1912, municipal regulations, domestic service, social conflict

\section{Entre tentatives réglementaires et domestiques organisés: la régulation municipale du service domestique. Ville de Buenos Aires, 1875-1912}

Cet article analyse une série de tentatives de régulation municipale du service domestique dans la ville de Buenos Aires à la fin du XIXe siècle et au début du XXe siècle. Corrélativement à ces processus, une série d'expériences d'organisation des travailleurs et des travailleuses est reconstituée pour mieux saisir ce cadre normatif et réglementaire. L'article montre alors que la régulation du service domestique répond à un univers de problèmes associés à la croissance et aux transformations de la ville. Les sources utilisées sont des ordonnances et des règlements publiés dans les digests municipaux, des projets qui furent présentés et traités lors des sessions ordinaires du Conseil Délibératif, la presse ouvrière, des magazines illustrés entre autres documents de l'époque.

Mots clé: Buenos Aires, 1875-1912, normes municipales, service domestique, conflit social

Recibido: 21 de enero de 2016 / Aceptado: 7 de abril de 2016

$\left.{ }^{*}\right)$ Doctora en Historia. Investigadora CONICET y profesora Universidad de San Andrés, Argentina.

ceciallemandi@yahoo.com.ar 
Revista Historia y Justicia

ISSN 0719-4153 revista.historiayjusticia.org

Nº6 - Santiago de Chile, abril 2016, p. 103-136

\title{
Entre tentativas reglamentarias y sirvientes organizados: la regulación municipal del servicio doméstico. Ciudad de Buenos Aires, 1875-1912
}

\author{
Cecilia L. ALLEMANDI
}

En la ciudad de Buenos Aires de fines del siglo XIX y principios del XX, el servicio doméstico era uno de los segmentos más significativos del mercado de laboral1. Aunque estuvo conformado en gran medida por mujeres, los varones también participaron de diferentes actividades ${ }^{2}$. Por otra parte, la cuantiosa participación de niños y la incorporación masiva de trabajadores provenientes de Europa nos permiten pensar que este sector se constituyó en una de las principales puertas de entrada al mercado de trabajo urbano ${ }^{3}$.

El servicio doméstico era un espacio complejo de trabajos y relaciones que implicaba el desempeño de un sinnúmero de tareas, que variaban de acuerdo a las exigencias de los patrones. Limpiar, fregar, lavar, planchar, cocinar, servir la mesa, cuidar niños, podían formar parte de extensas jornadas de trabajo. A los y las trabajadoras del sector se las denominaba generalmente "sirvientes" o "domésticos". No obstante, también existían otras figuras ocupacionales: amas de llaves, mucamos/as, niñeras, cocineros/as, jardineros, cocheros, valets, porteros, etc. Todos ellos contribuían a la reproducción cotidiana de los miembros de las familias, aunque no de forma exclusiva ya que, como veremos, los límites

\footnotetext{
1 Las cifras son elocuentes. En 1869, el sector absorbió alrededor del 20\% del total de la población "con ocupación", sumando unos 20.000 sirvientes. Su importancia relativa fue disminuyendo hasta representar alrededor del 8\% para 1914. Aún así, en términos absolutos este segmento laboral siguió engrosando sus filas y cuadruplicó su número, superando los 90.000 sirvientes.

${ }^{2} \mathrm{El}$ predominio de las mujeres se fue acrecentando pasando de representar el $70 \%$ al $90 \%$ de los sirvientes entre 1869 y 1914. La relación entre éstas y los trabajos domésticos se reafirmó y con el tiempo este espacio laboral se constituyó en un reducto eminentemente femenino.

3 Para 1869 la proporción de "nativos" y "extranjeros" en el servicio doméstico estaba equiparada. Para fines de 1880 los inmigrantes superaban ampliamente a los y las hijas del país, representando casi el $60 \%$ de la población que trabajaba en el sector. La presencia de extranjeros seguirá incrementándose hasta llegar a representar más del $70 \%$ del servicio doméstico porteño.
} 
entre el espacio doméstico y el de los negocios eran difusos y permeables. Estaban quienes se colocaban "con cama" (modalidad más extendida), quienes trabajaban "sin cama" o "por horas". Cada una de estas modalidades daba lugar a relaciones y formas de dependencia muy diferentes.

A partir del último cuarto del siglo XIX, las autoridades locales buscaron regular el servicio doméstico. Resulta interesante analizar estos intentos reglamentarios del poder municipal, ya que se trató de una de las instancias de la administración estatal que más afectó a los sirvientes, y aún no ha recibido atención suficiente. En efecto, desde el campo académico y desde las organizaciones políticas y gremiales se ha subrayado el desamparo que han experimentado los y las trabajadoras del servicio doméstico en relación a los avances del Derecho Laboral y de la Protección Social en distintos contextos nacionales y regionales ${ }^{4}$. Es que en Argentina, al igual que en otros países de América Latina, este sector fue uno de los más relegados, tanto respecto de las condiciones de trabajo y salariales como de su marco legal ${ }^{5}$. Excluido una y otra vez de los beneficios que la legislación del trabajo comenzaba a otorgar a otros grupos o sectores de actividad desde principios del siglo pasado (me refiero a la sanción de leyes como la del descanso dominical de 1905, la reglamentaria del trabajo de mujeres y menores de 1907, la de accidentes de trabajo de 1915 -por mencionar sólo las que se corresponden con el período de estudio), los reclamos y los proyectos por incorporarlo comenzaron de forma temprana pero en general fracasaron ${ }^{6}$. Y si bien en 1928, se prohibió el trabajo de menores de 14 años en el sector (Ley $n^{\circ} 11.317$ ) hubo que esperar al año 1956 para que se legislaran las relaciones que resultaban de la prestación de servicios de carácter doméstico, con la sanción del "Régimen de trabajo y previsión del personal que presta servicios en casas de familia" (Decreto-Ley n³26/56) 7 .

\footnotetext{
${ }^{4}$ Una referencia pionera ineludible para América Latina: Chaney Elsa \& García Castro Mary (eds.), Muchacha, cachifa, criada, empleada, empregadinha, sirvienta y más nada, Nueva sociedad, Caracas, 1993 ( $1^{\text {a }}$ edición en español). Algunos abordajes más actuales: Oficina Internacional del Trabajo, Trabajo decente para los trabajadores domésticos, OIT, Ginebra, 2009; Valenzuela, María Elena, "Esfuerzos concertados para la revaloración del trabajo doméstico remunerado en América Latina", en Valenzuela, María Elena \& Mora, Claudia (eds.), Trabajo doméstico: un largo camino bacia el trabajo decente, OIT, Santiago de Chile, 2009; Pereira, Milena \& Valiente, Hugo, Regimenes jurídicos sobre trabajo doméstico remunerado en los Estados del MERCOSUR, Cotidiano Mujer, Montevideo, disponible en http://www.cotidianomujer.org.uy/regimenes_esp2010.pdf, consultado 13 de noviembre de 2013.

${ }^{5}$ Véase Tizziani, Ania, "El Estatuto del Servicio Doméstico y sus antecedentes: debates en torno a la regulación del trabajo doméstico remunerado en la Argentina", Nuevo Mundo Mundos Nuevos, n¹3, 2013, http://nuevomundo.revues.org/65153; Birgin, Haydée, "Sin acceso a la justicia: el caso de las trabajadoras domésticas en la Argentina", en Valenzuela, M. E. \& Mora, C. (eds.), Trabajo doméstico: un largo camino, Op. Cit.

${ }^{6} \mathrm{El}$ primer proyecto (fallido) para incorporar al servicio doméstico a la ley de accidentes de trabajo data de 1916. Fue el diputado socialista Augusto Bunge el que presentó el proyecto.

${ }^{7}$ El llamado "Estatuto del Servicio doméstico" estuvo vigente por más de cincuenta años y compartió algunas características centrales con muchas legislaciones de los países de la región. Una de ellas fue su exclusión del marco general del derecho laboral en función de su "particularidad": en Argentina las empleadas domésticas quedaron fuera de la Ley n²0.744 de Contrato de Trabajo. Véase Tizziani, A., "El Estatuto del Servicio Doméstico", Op.Cit.
} 
Ahora bien, para el período en estudio, fue el Código Civil el que ofreció el marco de referencia para la regulación del servicio doméstico. No hay que perder de vista que antes del desarrollo del derecho laboral, a fines del siglo XIX y principios del siglo XX, eran los códigos legales -civiles y comerciales- los dos corpus más importantes que hacían referencia a la "venta del trabajo"8. En su artículo 1624, el Código estableció que el sector debía ser reglamentado por disposiciones especiales: "el servicio de las personas de uno y otro sexo que se conchabaren para servicio doméstico, [debía] ser juzgado por las ordenanzas municipales o policiales de cada pueblo (...)"'.

En concordancia con lo instituido, a partir de la década de 1870, la administración municipal de la ciudad de Buenos Aires intentó regular al sector en diversas oportunidades. Algunos de los proyectos fueron sancionados, mientras otros, una vez presentados en el Concejo Municipal (luego Deliberante), no volvieron a ser considerados. De todas formas, esto no disminuye su valor heurístico; por el contrario, creemos que estas propuestas normativas permiten conocer ciertos aspectos de las condiciones de vida y de trabajo de los y las sirvientes, comprender cuáles eran las preocupaciones que suscitaban, las formas mediante las cuales el poder municipal se propuso intervenir en ese espacio social de trabajo, y las implicancias que tuvieron esas tentativas.

Este artículo se centra en los intentos de regulación municipal del servicio doméstico en la ciudad de Buenos Aires, entre 1875 y 1912. Incorpora el análisis de los marcos normativos a las problemáticas de la historia laboral y procura contribuir al conocimiento de este sector del mundo del trabajo urbano. Analiza las preocupaciones que motivaron las regulaciones del sector, las (re)acciones sociales que generaron estas tentativas y sus influjos en el proceso de construcción de aquel marco regulatorio. Se propone demostrar que la regulación del servicio

\footnotetext{
${ }^{8}$ Conforme a la tradición liberal, consideraban a la sociedad como un conjunto de individuos -libres e iguales-, en el que el vínculo contractual se presentaba como la forma más evolucionada del compromiso social. La preeminencia del "contractualismo" fundaba su razón en el libre consentimiento de quienes quedaban afectados en la relación contractual. A su vez, reafirmaba la idea de la igualdad de las partes en la medida que presuponía que las mismas contaban con la posibilidad de rechazar el acuerdo. La figura del contrato marcaba claramente su pertenencia al ámbito de lo privado, ya que vinculaba bilateralmente a los individuos. De todas formas, ese acuerdo implicaba necesariamente a un tercero garante, el Estado, el que, al tiempo que regulaba la acción, ofrecía el marco legal que lo hacía posible. Un análisis de la forma jurídica que adoptó el vínculo laboral bajo la tradición civil se encuentra en Stagnaro, Andrés, Los tribunales de trabajo como el escenario del conflicto entre el capital y el trabajo. 1948-1960, Tesis de Doctorado en Historia, Universidad Nacional de La Plata, 2012, p. 79.

9 Código Civil de la República Argentina, Pablo E. Coni, Buenos Aires, 1874, Capítulo VIII, "De la locación de servicios", artículo n¹624. Aunque en la actualidad este artículo es más declarativo que real, cabe señalar que aún sigue vigente. En el año 2004, la diputada María Lelia Chaya presentó un proyecto de ley para la derogación de este artículo y el subsiguiente (1624 y 1625). Sin embargo a pesar de obtener media sanción en el Senado, no volvió a ser tratado y perdió estado parlamentario en febrero de 2005 . Véase http://1.hcdn.gov.ar/dependencias/clgeneral/temario_diputados/proyectos\%20temario/456-d-04.htm, consultado el 04 de marzo de 2010.
} 
doméstico respondió a un universo de problemas asociados al crecimiento de la población urbana y su extranjerización, al creciente anonimato, al miedo a la simulación y, por fin, al aumento de la criminalidad urbana. Trabaja con ordenanzas y reglamentos municipales, proyectos presentados y tratados en las sesiones ordinarias del Consejo Deliberante, prensa obrera y magazines ilustrados, entre otros documentos de época.

\section{Reglamentaciones que generan resistencias}

Desde el último cuarto de siglo XIX, Buenos Aires fue el epicentro de una serie de transformaciones que alteraron sustancialmente su fisonomía ${ }^{10}$. La consolidación de la economía del país en el mercado mundial (boom agroexportador) y el aluvión inmigratorio convulsionaron a la ciudad, ya que por su puerto no sólo desfilaron mercancías sino también millones de inmigrantes, provenientes de Europa, que se aventuraban a cruzar el océano ${ }^{11}$.

Antes del cambio de siglo, la ciudad se había convertido en una gran metrópolis ${ }^{12}$. Sus habitantes fueron testigos del despliegue de un conjunto de sorprendentes procesos al tiempo que tuvieron que lidiar con los clásicos problemas de las modernas urbanizaciones: el déficit habitacional, la pobreza, las epidemias, el aumento del crimen, la prostitución, la protesta obrera, el creciente influjo del socialismo y el anarquismo, entre otros fenómenos ${ }^{13}$.

\footnotetext{
${ }^{10}$ La ciudad experimentó el crecimiento más espectacular de su historia. Para 1869 contaba con poco menos de doscientos mil habitantes y para 1895 albergaba más de medio millón; este número se triplica en veinte años, superando el millón y medio de habitantes para 1914. Recchini de Lattes, Zulma, "Crecimiento explosivo y desaceleración”, en Romero, J. L. \& L. A. Romero (Dirs.), Buenos Aires. Historia de cuatro siglos, Tomo II, Altamira, Buenos Aires, 1983.

${ }^{11}$ Entre 1870 y 1914 arribaron al país alrededor de 6 millones de europeos. Venían a estas tierras en busca de trabajo, atraídos por una diferencia de salarios favorable y por las posibilidades que este destino les ofrecía. Se establecieron en gran medida en unas pocas provincias del litoral y de la pampa húmeda y sobre todo en la ciudad de Buenos Aires. Entre ellos, los italianos sumaron alrededor de 2.000.000; los españoles 1.400.000; los franceses, 170.000; los rusos, 160.000. La curva de la inmigración muestra dos fases prolongadas de expansión, interrumpidas por la crisis del '90. En la segunda de las fases, la Argentina llegó a sus máximos históricos antes del inicio de la Primera Guerra Mundial. En ese período recibió un aluvión inmigratorio inferior al de los Estados Unidos, pero superior al de Canadá y Brasil. Devoto, Fernando, Historia de la inmigración en la Argentina, Sudamericana, Buenos Aires, 2009, p. 247.

12 Referencias sobre estos procesos se encuentran en: Scobie, James R., Buenos Aires. Del centro a los barrios, 18701910, Solar/Hachette, Buenos Aires, 1977; Francis Korn, Buenos Aires 1895. Una ciudad moderna, Editorial del Instituto, Buenos Aires, 1981; Zimmermann, Eduardo A., "La sociedad entre 1870 y 1914", en Academia Nacional de la Historia, Nueva Historia de la Nación Argentina, Tomo IV-Tercera Parte: La configuración de la República independiente 1810-c.1914, Editorial Planeta, Buenos Aires, 2000.

13 Véase: Liernur, Jorge F., "La ciudad efímera, consideraciones sobre el aspecto material de Buenos Aires, 18701910", en Liernur, Jorge F. \& Silvestre, Graciela, El umbral de la metrópolis. Transformaciones técnicas y cultura en la modernización de Buenos Aires (1870-1930), Editorial Sudamericana, Buenos Aires, 1993; Armus, Diego, "El descubrimiento de la enfermedad como problema social" y Liernur, Jorge F., "La construcción del país urbano", ambos en Lobato, Mirta Z. (dir.), Nueva Historia Argentina. El progreso, la modernización y sus límites (1880-1916), Tomo 5, Editorial Sudamericana, Buenos Aires, 2000. Sobre la emergencia de la cuestión social: Zimmermann, Eduardo
} 
Las formas de concebir el orden social, el conflicto, el trabajo, la familia, los roles femeninos y masculinos, el rol del Estado, fueron sacudidas en sus fundamentos y ocuparon un lugar en la agenda pública. Las instituciones públicas -que se encontraban en plena expansión y consolidación de sus funciones- tuvieron que posicionarse en relación a estos temas y participaron en su definición.

En este marco, la sociedad porteña buscó regular algunas actividades laborales, intentando someterlas a una reglamentación y control. Muchas de estas estas tentativas quedaron plasmadas en los Digestos de Ordenanzas, Reglamentos, Acuerdos y Disposiciones de la Municipalidad de Buenos Aires, que comenzaron a publicarse en el año 1873. Estos compendios debían recoger todas las disposiciones vigentes, consignando asimismo modificaciones o sustituciones que se hubieran efectuado en el cuerpo normativo entre una publicación y otra ${ }^{14}$.

En estos compendios, el orden de presentación de las disposiciones no respondió a la fecha de sanción de las mismas, sino a grandes temas de interés público. Así, por ejemplo, el Digesto de 1877 introducía, en la materia "Higiene Pública", el tratamiento dado a la prostitución, tratada junto a reglamentos sobre mercados de abasto, mataderos públicos, hospitales y hospicios, limpieza pública y vacunación de niños, entre otros. De la misma forma, disposiciones de lo más variadas sobre materias inflamables, establecimientos a vapor, inspección del alumbrado público, reglamentos y tarifas de los carruajes de la plaza, se presentaban junto a ordenanzas que prohibieron la mendicidad y reglamentaron a los mozos de cordel y al servicio doméstico bajo el gran rótulo de la "Seguridad".

Prostitutas, changadores, cocheros, carreros, mozos de cordel, sirvientes y camareras fueron objeto de intervención temprana de los poderes públicos locales, aunque remitieron a diferentes universos dentro de la amplia gama de problemas urbanos.

El 7 de mayo de 1875 se discutió un proyecto sobre servicio doméstico elaborado por los señores Alcorta, Lagos García, Perisena y Victorica ${ }^{15}$. Los representantes del poder municipal justificaron su presentación señalando que el Código Civil había dejado al cuidado de las municipalidades la reglamentación de las relaciones entre los sirvientes y los patrones, y que era necesario dar cima a esa exigencia, reclamada según necesidades conocidas por todos: el servicio doméstico "había llegado á ser una plaga, cuyas malas consecuencias era necesario remediar". Según consta en las actas, el proyecto fue aprobado en general y, en la discusión

A., Los liberales reformistas. La cuestión social en la Argentina 1890-1916, Sudamericana-Universidad de San Andrés, Buenos Aires, 1995; Suriano Juan (comp.), La cuestión social en Argentina 1870-1943, La colmena, Buenos Aires, 2000. ${ }_{14}$ Por su parte, los debates que suscitaron y los proyectos que no fueron sancionados quedaron registrados en las versiones taquigráficas del Concejo Deliberante de la ciudad. Ambas fuentes fueron consultadas en la Dirección General Centro Documental de Información y Centro Legislativo (CEDOM).

${ }^{15}$ CEDOM, Actas de la Comisión Municipal de la Ciudad de Buenos Aires correspondiente al año 1875, Publicación ordenada por el Presidente del H. Concejo Deliberante Dr. Carlos M. Coll, Buenos Aires, Talleres Gráficos “Optimus”, 1912. 
en particular, se plantearon una serie de modificaciones que fueron aceptadas sin demasiados rodeos, quedando sancionado ese mismo día ${ }^{16}$.

El Reglamento constaba de ocho capítulos que atendieron a una gran variedad de aspectos: la definición de las ocupaciones que quedarían comprendidas dentro del servicio doméstico; las formas de registro e identificación de los sirvientes; las relaciones entre éstos y sus patrones; el control médico de las amas de cría; el servicio de menores de edad; las agencias de conchabo, entre otros. Un repaso por los elementos más significativos de este cuerpo normativo nos permitirá conocer su naturaleza y comprender mejor las razones de las reacciones que suscitó.

Las "Disposiciones Generales" explicitaron primero quiénes serían considerados "sirvientes" a los efectos de la ordenanza: "los cocineros y cocineras, los mucamos y mucamas de toda clase y denominación, las amas de cría, las niñeras, los cocheros, los lacayos y palafreneros de casas particulares, los porteros y los mozos de hoteles, cafés, casas de comida y casas de huéspedes"17.

El criterio para considerar a esta variedad de ocupaciones y actividades bajo la categoría de "sirvientes" no parece haber sido el lugar de trabajo, porque se desempeñaban en distintos espacios (la casa, la calle, los locales comerciales). Tampoco parece haber incidido el tipo de actividades, ya que se trataba de tareas diversas que dependían en gran medida de las exigencias -siempre variables- de los patrones. Lo que primó parece haber sido la forma de caracterizar las relaciones que se entretejían entre los y las trabajadoras y sus patrones. En efecto, la mayoría de ellos hacía arreglos para vivir en su lugar de trabajo y compartían con sus patrones un espacio privado, surgido a partir de la convivencia. Estos arreglos implicaban una cuota de cotidianeidad, proximidad e intimidad que permitía pensar esas relaciones como si fueran de "tipo domésticas"18.

\footnotetext{
${ }^{16}$ Los representantes del proyecto rechazaron de plano el argumento de "inoportunidad" que algunos de los presentes alegaron. También rebatieron el planteo de que se iban a generar gastos en momentos en que los recursos públicos eran sumamente escasos (debido a la crisis económica que se transitaba en esos años), explicando que serían cubiertos con las "cuotas de imposición" establecidas por el mismo Reglamento. CEDOM, Actas de la Comisión Municipal de la Ciudad de Buenos Aires correspondiente al año 1875.

${ }_{17} \mathrm{CEDOM}$, Reglamento para el servicio doméstico, sancionado el 7 de mayo de 1875 (Reglamento), Capítulo I, "Disposiciones Generales", artículo $1^{\circ}$.

${ }^{18}$ En su estudio sobre la sociabilidad en los cafés y despachos de bebidas en Buenos Aires, Sandra Gayol ha señalado que en estos locales las mujeres se desempeñaban como lavanderas o cocineras en la trastienda (ya que generalmente no atendían el mostrador), y que las fuentes por ella relevadas referían a ellas como "sirvientas". Observó que generalmente empleados y patrones cohabitaban, y que esto daba lugar a un contexto "familiar" de trabajo y de vida entre ellos, lo que no impedía, por cierto, la existencia de enfrentamientos violentos y de relaciones conflictivas. Gayol, Sandra, Sociabilidad en Buenos Aires: hombres, honor y cafés, 1862-1910, Ediciones del Signo, Buenos Aires, 2000, p. 51.
} 


\section{Revista Historia y Justicia}

ISSN 0719-4153 revista.historiayjusticia.org

Nº6 - Santiago de Chile, abril 2016, p. 103-136

Una vez identificadas las figuras ocupacionales que serían objeto de regulación, se procedía a establecer la modalidad que asumiría el registro y control de esa población. Quienes tuvieran o quisieran tomar la ocupación de sirviente deberían ser inscriptos en la "Oficina de Servicio Doméstico" (la que sería creada a partir de ese mismo acto normativo). Asimismo, deberían portar una libreta con una serie de datos personales y laborales que sería expedida por dicha dependencia pública ${ }^{19}$.

La primera inscripción y la entrega de libretas serían efectuadas por empleados municipales "a domicilio" (casa por casa). De esta forma, quienes tuvieran personas a su servicio tendrían la obligación de registrarlas (declararlas). A su vez, en adelante, cualquier cambio en la situación laboral de los sirvientes debería notificarse a la Oficina. Quienes dejaban el servicio de una familia y tomaban el de otra, debían manifestarlo para su registro y anotación en un "libro de certificado de conducta". Quienes cambiaban de ocupación, podían borrarse del registro municipal y solicitar que se les extendiera un certificado. Por último, se instituyó que tanto el "registro de inscripción de sirvientes" como el "libro de certificado de conducta", estuvieran a disposición de los jueces y de la policía, "siempre que lo solicitasen para la averiguación de crímenes"20.

Para poder acreditar la identidad y la honestidad de los sirvientes, y evitar que se colaran "elementos malsanos" en el gremio, la legislación detalló las características de las libretas y la obligatoriedad de su uso. Para ello explicitó los criterios que garantizarían su fidelidad y veracidad (con sellos y firmas, entre otras autenticaciones); los costos de las mismas; y las multas por extravío (que serían de $\$ 5$ si sus propietarios podían justificar la pérdida y de $\$ 200$ si no podían "dar pruebas") ${ }^{21}$.

En lo que a los patrones respecta, se les prohibió tomar personas para el servicio si no poseían libreta y certificado de buena conducta confeccionado por la última persona que la tuvo a su servicio. Todo "jefe de casa" debía apuntar en la libreta de su sirviente la fecha de entrada y su ocupación (como chofer, cocinero/a, ama de llaves, niñera, etcétera) y, si ésta dejaba su servicio, debía hacer constar la razón de su salida y detallar cómo había sido su conducta "bajo sus órdenes". Asimismo, al tomar un sirviente debían dejar constancia del sueldo y las condiciones del ingreso al puesto en unos "boletos de contrato", que serían entregados, para ser completados, de forma gratuita en la Oficina ${ }^{22}$.

\footnotetext{
19 Tanto en el registro como en la libreta debía constar: el número de orden, el nombre del sirviente, la filiación (donde se consignaban algunos rasgos físicos que debían permitir particularizarlo/a), la nacionalidad, la edad, su estado, la clase de ocupación, el nombre y el domicilio de la persona que la tenía a su servicio.

${ }^{20}$ CEDOM, Reglamento, Capítulo I, "Disposiciones Generales", artículos $2^{\circ}$ al $6^{\circ}$.

${ }^{21}$ CEDOM, Reglamento, Capítulo II, "De las Libretas", artículos $7^{\circ}$ al $10^{\circ}$.

22 CEDOM, Reglamento, Capítulo II, "De las Libretas", artículos $7^{\circ}$ al $10^{\circ}$.
} 
La ordenanza avanzó sobre otros aspectos de las relaciones entre patrones y sirvientes. Estableció los términos en los que debía finalizar el vínculo laboral. Ningún sirviente podía abandonar la casa de sus patrones sin un aviso previo (con diez días de anticipación) a menos que: una enfermedad lo imposibilitara "visiblemente" para el servicio; que no se cumpliera con el pago de su sueldo en el tiempo convenido; o bien, que sufriera maltrato físico. Por su parte, ningún patrón podía despedir a su sirviente sin previo aviso (con diez días de anticipación), a menos que le abonase la parte del sueldo correspondiente a esos días o que mediasen alguna de las siguientes circunstancias: que no cumpliera su servicio; que se enfermara y lo imposibilitara en su desempeño; que llegase ebrio; que se insolentase con él; o que hubiese cometido robo o algún otro delito 23 .

Además de establecer los plazos y los posibles motivos de ruptura del vínculo laboral, el reglamento explicitaba algunas de las obligaciones correspondientes a cada una de las partes mientras persistía el vínculo. Para los sirvientes, pueden destacarse los siguientes compromisos: "obedecer en todo" a su patrón (a menos que sea ilícito o contrario a lo convenido); vigilar los intereses del mismo y evitar (en lo posible) cualquier daño a que se hallase expuesto; responder por las pérdidas y daños que sufriese por culpa suya.

Por su parte, el patrón debía "tratar bien" a su sirviente y darle habitación y alimento apropiado; subsanar los daños o pérdidas que sufriere por culpa suya o por defender sus intereses; en caso de enfermedad, se indicaba socorrerlo "a costa de su sueldo, si no quisiese hacerlo por caridad" y, en caso de que fuese un mal contagioso o que se prolongase más de ocho días, debía conducirlo a un hospital o al lugar que el sirviente desease ${ }^{24}$. Como cierre de esta sección referida a las relaciones entre las partes, se le concedió al patrón la posibilidad de descontar al sirviente de su sueldo una suma equivalente a los daños y pérdidas que el mismo le hubiese causado.

Como se desprende, a los sirvientes se les reclamaba obediencia y lealtad; a los patrones, cierta humanidad en el trato. Las pautas establecidas parecieron exceder las de una relación meramente laboral y evidenciaron la importancia que tenía la dimensión moral y afectiva en esos vínculos, en la medida en que se requerían (normativizaban) una serie de comportamientos y actitudes que responden a esos órdenes.

Los capítulos subsiguientes incluyeron menciones especiales sobre dos sujetos o grupos en particular: las amas de cría y los menores de edad. En el caso de las primeras, a las exigencias de registro y la obligatoriedad de la libreta se sumó el control médico por parte del municipio. Quedarían asentadas en la libreta las condiciones físicas en las que se encontraban. El

${ }^{23}$ CEDOM, Reglamento, Capítulo III, "De la relación entre patrones y sirvientes", artículos $15^{\circ}$ y $16^{\circ}$.

${ }^{24}$ CEDOM, Reglamento, Capítulo III, Art. $17^{\circ}$ y $18^{\circ}$. 
tratamiento dado a las amas se acercaba más al procedimiento implementado con las prostitutas, una intervención de tipo médico-higiénica por parte de las autoridades públicas ${ }^{25}$.

En lo que al vínculo laboral respecta, en el caso de las amas se estableció que el servicio duraría lo que necesitara la nutrición y crianza de la criatura. Sólo se podía justificar el despido antes de terminar el contrato en caso de: fallecimiento de la criatura; maltrato; enfermedad o vicios que tornasen peligrosa la lactancia (para el niño); falta o descomposición de la leche; robo u otro delito cometido en la casa. Los motivos que justificaban el abandono de la crianza eran similares a los del resto de los sirvientes: falta de pago, maltrato físico, enfermedad, etc. Pero en cambio, si las amas de crían eran despedidas sin razón, tenían derecho a cobrar sus sueldos hasta el fin del contrato. Por último, se prohibía a las amas criar a más de un niño a la vez, "bajo la pena de multa o prisión" 26.

El caso de los menores de edad que trabajaban como sirvientes también mereció una mención particular. El reglamento reconoció dos tipos de colocación diferentes, que supusieron obligaciones distintas para sirvientes y patrones. Por un lado, hacía referencia a los menores colocados como "sirvientes a sueldo", quienes estarían afectados por la normativa al igual que los adultos, aunque serían los padres o tutores los responsables de su cumplimiento, al igual que de manejar los contratos por el servicio de los mismos. Por otro, reconocía la existencia de menores "en servicio de sus tutores o encargados de alimentarlos y educarlos". Estos no serían afectados por la reglamentación ya que estaban exceptuados de la obligación de la inscripción en la Oficina, por lo tanto, no serían identificados ni controlados por dicha dependencia pública ${ }^{27}$.

Estas disposiciones diferenciaron los arreglos de trabajo entre particulares (es decir, entre los padres o familiares de los niños y los patrones), de las entregas y colocaciones de aquellos menores que ingresaban al "ciclo tutelar" de las defensorías, la Sociedad de Beneficencia, entre otros. Estas instituciones ubicaban niños y jóvenes de ambos sexos en hogares

\footnotetext{
${ }^{25}$ Véase Guy, Donna J., El sexo peligroso: la prostitución legal en Buenos Aires, 1895-1955, Sudamericana, Buenos Aires, 1994.

${ }^{26}$ CEDOM, Reglamento, Capítulo IV, "De las amas de lactancia", artículos 20 al 26. Si bien en esta primera instancia normativa las amas de cría fueron asimiladas a los sirvientes, con el cambio de siglo comenzaron a ser objeto de un tratamiento diferencial y a asociarse a políticas de "Protección de la Primera Infancia". La lactancia en tanto actividad asalariada fue constituyéndose en un problema en sí mismo, ya que médicos e higienistas lo asociaron directamente al fenómeno de la mortalidad infantil. De allí que los intentos de regulación y control posteriores estuvieron destinados a ofrecer al público nodrizas sanas, que garantizaran el buen crecimiento y desarrollo de los niños durante la primera infancia. Ello se lograba mediante el control médico de las mujeres que vivían del amamantamiento y la regulación del funcionamiento de las agencias de colocación especializadas en ese rubro. Con esto quiero señalar que los intentos de regulación de la lactancia asalariada remiten a otro universo de problemas. Analizo estos temas en otro artículo de mi autoría: "Las amas de leche y la regulación del mercado de la lactancia en la ciudad de buenos Aires (1875-1911)", Revista Mora, ISSN 1853-001X (en prensa).

${ }^{27}$ CEDOM, Reglamento, Capítulo V, "De los menores de edad", artículos $27^{\circ}$ al $29^{\circ}$.
} 
extraños, generalmente en calidad de sirvientes. La mayoría de ellos no cobraba sueldos por los servicios prestados ya que el Código Civil establecía en su artículo 1425 que "quien hubiese criado a alguna persona, no [podía] ser obligado a pagarle sueldos por servicios prestados, hasta la edad de quince años cumplidos". De la misma forma, añadía, tampoco podían ser "obligados a pagar sueldos los tutores que conservaron en su compañía a los menores de quince años, por no poder darles acomodo" 28 .

La ordenanza de 1875, también se encargó de regular la operatoria de las "agencias de conchavos" [sic]. Esta función sería vehiculizada por la Oficina llevando un control de las mismas; por eso, antes de iniciar sus actividades debían registrarse en ella. Asimismo, quienes estuvieran a cargo de estas casas debían acreditar buena conducta. No podían colocar sirvientes que no estuviesen registrados, que no tuviesen libreta o certificado de su conducta (a menos que probasen que los patrones se habían negado a completarlo). Se les prohibió igualmente colocar a quienes hubiesen sido expulsados por robo u otro delito en las casas en las que estaban empleados. Asimismo, las agencias debían llevar un registro de los datos personales y laborales de los sirvientes interesados, y también de todos los conchabos realizados (no así de los patrones). Toda esa información debía ser presentada semanalmente a la Oficina. Por último, se estableció que los agentes debían cobrar su comisión una vez efectuada la colocación, y no de forma anticipada, como usualmente ocurría ${ }^{29}$.

En línea con las disposiciones anteriores, el objetivo de la regulación de estas agencias fue dar garantías y seguridades a los patrones al momento de contratar servicio, sin solicitarles a ellos, sistemáticamente, ni las mismas informaciones, ni niveles de registro y control.

En el capítulo sobre las "disposiciones penales", la ordenanza municipal impuso sanciones económicas dependiendo de la falta que se cometiese. En caso de infracción, se establecieron multas que iban desde los $\$ 200$ a los $\$ 5000^{30}$. Ninguno de los sujetos a quienes estaba dirigida la legislación (patrones, sirvientes y agencias) estaba exento de las penas y sanciones. Por último, se establecía que las demandas sobre asuntos domésticos debían realizarse ante los Jueces de Paz y Comisarios de Policía ${ }^{31}$.

Como puede observarse, la ordenanza 1875 abordó una gran diversidad de aspectos que hicieron a la regulación del servicio doméstico, y demandó la creación de una dependencia

\footnotetext{
${ }^{28}$ Código Civil, Capítulo VIII, "De la locación de servicios", artículo 1625. Al igual que en el caso de las amas de leche, la presencia de niños en el servicio doméstico merece un análisis aparte. Algunas dimensiones de este fenómeno han sido abordadas en otro artículo de mi autoría: "Niños Sirvientes y 'criados': el trabajo infantil en el servicio doméstico (ciudad de Buenos Aires, fines del siglo XIX-principios del siglo XX)", Cuadernos del IDES, $\mathrm{n}^{\circ} 30$, ISSN 1668-1053, octubre de 2015, p. 11-38, disponible en http://ides.org.ar/wpcontent/uploads/2012/03/Cuadernos-del-IDES-N\%C2\%BA-30-Octubre-2015.pdf .

${ }^{29}$ CEDOM, Reglamento, Capítulo VI, "De las agencias de conchabo", artículos 30 al 37.

${ }^{30}$ Se trató de cifras realmente elevadas, tanto para los sirvientes como para los patrones.

${ }^{31}$ CEDOM, Reglamento, Capítulo VII, "Disposiciones penales", artículos 38 al 52.
} 
pública que se encargaría de su observancia. En parte, su contenido nos retrotrae a los viejos contratos de trabajo y a las libretas de conchabo, herramientas legales que fueron implementadas para disciplinar tanto social como laboralmente a los trabajadores ${ }^{32}$. De todas formas, notamos que en este texto normativo subyacía también el problema (¿más moderno?) de la seguridad en el contexto del anonimato urbano y que, justamente, los esfuerzos por identificar y controlar el movimiento de los sirvientes respondían en gran medida a la necesidad de resguardar a los patrones. Que este Reglamento para el servicio doméstico haya sido publicado bajo el título de "Seguridad" habla en definitiva del lugar asignado a este tópico, dentro del universo de los problemas urbanos sobre los que las autoridades procuraron intervenir.

Si bien la ordenanza fue sancionada, nunca pudo implementarse. Mirándolo retrospectivamente, algunos concejales señalaron que era demasiado detallista y presentaba dificultades en su implementación, mientras otros plantearon problemas presupuestarios. Finalmente, en distintas fuentes documentales quedó asentado que el reglamento no pudo aplicarse porque fue resistido, lo que nos puede estar hablando de la existencia de fuerte oposición pero también de una gran debilidad del poder municipal.

Unos años más tarde, se insistió en la necesidad de poner en vigencia el Reglamento ${ }^{33}$. Además de la cuestión presupuestaria, se propuso un nuevo "modelo de libreta" que serviría para la inscripción del servicio doméstico, y el "formulario para los boletos de contrato" entre los patrones y los sirvientes. Asimismo se plantearon una serie de modificaciones para facilitar la inscripción de los últimos y economizar gastos ${ }^{34}$.

\footnotetext{
${ }^{32} \mathrm{La}$ formación de un mercado de trabajo y la consecuente libre oferta y demanda del trabajo en tanto mercancía fue un proceso que cristalizó recién hacia fines del siglo XIX en el litoral pampeano. Hasta entonces se tomaron medidas para canalizar a los trabajadores hacia sectores de actividad que así lo demandaban, limitar su libertad de movimiento y retenerlos en un trabajo regular. Lobato, Mirta Z., "Los trabajadores en la era del progreso", en Lobato, Mirta Z. (dir.), Nueva Historia Argentina. El progreso, la modernización y sus límites (1880- 1916), Tomo 5, Editorial Sudamericana, Buenos Aires, 2000, p. 468 y siguientes. Entre los mecanismos de control de mano de obra se puede mencionar el "régimen de aprendizaje", la legislación referida a "vagos y malentretenidos", la implementación del "pasaporte" (para moverse de un partido, una provincia o una ciudad a otra), la sanción del "Código Rural". Una descripción de estos instrumentos legales se encuentra en: Sábato, Hilda \& Romero, Luis Alberto, Los trabajadores de Buenos Aires. La experiencia del mercado, 1850-1880, Sudamericana, Buenos Aires, 1992, p. 178 y siguientes.

${ }^{33}$ El concejal Lindolfo Dávila señaló que era imposible avanzar en su implementación si no se establecía aquella "oficina especial" que iba a ser creada para tales fines. Encomendó así a la Inspección General a que autorizara ese gasto en el presupuesto, aunque, según consta en las actas, no obtuvo los resultados esperados, ya que la ordenanza permaneció en suspenso debido a que dicha dependencia nunca se expidió al respecto. Sesión del 25 de abril de 1879. CEDOM, Memoria del Presidente de la Comisión Municipal al Concejo correspondiente al ejercicio de 1879 (MCM), Tomo I, Imprenta de Martín Biedma, Buenos Aires, 1880, p. 256-258.

${ }^{34}$ El concejal sometía a consideración una decena de los artículos de la ordenanza anterior. Una de las propuestas era que la inscripción y entrega de libretas no se hiciera "a domicilio". Otra, que las personas afectadas por la ordenanza concurrieran a la "Oficina de Inspección General" (esta sería su nueva denominación) para ser
} 
Las propuestas para modificar aquella primera ordenanza no volvieron a ser consideradas. En efecto, en el año 1881 fue reeditado en su forma original el Reglamento de 187535. La pretensión de imponer la "libreta" a los sirvientes originó una serie de protestas entre los distintos trabajadores que fueron afectados por la medida. La corporación de los mozos de hoteles y los demás dependientes asimilados al servicio doméstico por la ordenanza resistieron su puesta en práctica por resultarles ofensiva ${ }^{36}$.

Una vez más, los efectos de la normativa quedaron suspendidos. No obstante, a tan sólo un año de esos incidentes, la Ley Orgánica Municipal en su artículo 47, inciso 4, estableció que el Concejo Deliberante debía dictar una ordenanza reglamentando el servicio doméstico ${ }^{37}$. Al parecer, persistía una incapacidad por parte de las autoridades públicas para intervenir en ese ámbito, aunque la administración local se amparaba señalando que las dos tentativas para hacer efectiva la normativa habían fracasado a causa del "mal elemento" al que no le convenía su implementación, y había "conseguido sublevar a la parte honrada y laboriosa, que podía exhibir siempre su libreta de buena conducta"38.

Con impulso renovado, en enero 1887 la municipalidad reeditó una vez más aquella vieja ordenanza ${ }^{39}$. En respuesta a esa decisión, los y las trabajadoras designados como "sirvientes" anunciaron la realización de una asamblea porque consideraron que la misma era "lesiva para su dignidad" 40 . Al tomar conocimiento de la convocatoria, la policía antepuso su prohibición al considerar que esa reunión podía alcanzar las "proporciones de un mitin”. Acto seguido, la Sociedad de Artes Culinarias de la Capital Federal -uno de los sectores asignados como "sirvientes"- declaró la huelga y convocó por telegrama a los mozos y cocineros de los hoteles que estaban en Mar del Plata, indicándoles que se plegaran a la medida de fuerza y a

registradas. Tanto el "registro de inscripción" como el "libro de certificados de conducta" servirían para facilitarles datos a Jueces y empleados de Policía para la averiguación de los delitos. Todo "Gefe de casa" [sic] que tomara un sirviente debía completar un boleto (por duplicado), donde quedaría asentado el sueldo y las condiciones en que entraría a su servicio (él guardaría un ejemplar firmado por el sirviente y le entregaría a éste otro firmado por él). El modelo del boleto sería el siguiente: "Conste que hoy he... (entrado o tomado) á... en calidad de... y por el sueldo mensual de...". Los mismos se entregarían gratis en la Oficina. Así, aquel patrón que no hiciera inscribir a sus sirvientes afrontaría una multa de 500 pesos. "Modificaciones presentadas por Lindolfo Dávila en la sesión de 26 de mayo de 1879". CEDOM, MCM, p. 256-258.

35 Marotta, Sebastián, El movimiento sindical argentino. Su génesis y desarrollo, Tomo I, período 1857-1907, Ediciones Lacio, Buenos Aires, 1960, p. 35.

${ }^{36}$ Marotta, S., El movimiento sindical argentino. Su génesis y desarrollo, Op. Cit, p. 35.

${ }_{37}$ CEDOM, Digesto de Ordenanzas, Reglamentos, Acuerdos y Disposiciones de la Municipalidad de la ciudad de Buenos Aires, por Mariano Obarrio, Publicación Oficial, 1884, p. 484.

38 CEDOM, Digesto de Ordenanzas, Reglamentos, Acuerdos y Disposiciones de la Municipalidad de la ciudad de Buenos Aires, por Mariano Obarrio, Publicación Oficial, 1884, p. 484.

${ }^{39}$ Marotta, S., El movimiento sindical argentino. Su génesis y desarrollo, Op. Cit., p. 46.

40 Resulta llamativo que la forma de denominar a los sujetos del conflicto sea siempre masculina, a pesar de la cuantiosa presencia de mujeres en el sector. Este llamado de atención vale tanto para las fuentes como para la bibliografía consultada. 
que retornasen cuanto antes a Buenos Aires, ya que muchos se habían trasladado allá solo por la temporada de verano. Por su parte, los cocheros -que también se consideraron afectados por la normativa-, resolvieron ir a la huelga.

El diario La Prensa tomó partido por los y las trabajadores, señalando que la ordenanza era "agraviante para su derecho, su libertad y su dignidad", aunque desaprobó la huelga, a la que calificó de "motín” y "alzamiento". Consideró que las disposiciones de la normativa eran "monstruosas" y sostuvo que no podían aplicarse en un país "libre". Su régimen, manifestaba, evocaba la esclavitud:

"una esclavitud peor que la del negro convertido en bestia, porque siendo libre, su honor, su crédito, sus medios de subsistencia, son entregados a sus patronos discrecionalmente, quienes los podrán perder para siempre con sólo inscribir en su libreta un certificado adverso a su moralidad y competencia" ${ }^{41}$.

A pesar de las resistencias que despertó en la opinión pública, la municipalidad no cedió ni rectificó su decisión, lo que no implica que haya tenido éxito en su aplicación. En efecto, hubo patrones que hicieron caso omiso y no acataron la normativa, aunque hubo otros que estuvieron resueltos a aplicarla ${ }^{42}$.

Para cerrar este recorrido, cabe señalar que ese mismo año se consideró un nuevo proyecto en el Concejo Deliberante, lo que nos permite suponer que a la tentativa anterior finalmente no se le pudo dar curso. Y si bien éste último tampoco prosperó, resulta sugestivo porque incorporó una modificación significativa ${ }^{43}$. En ese nuevo texto se estableció que formaría parte del servicio doméstico "toda persona que se [conchabara] en el servicio privado, por un salario mensual, como mucamo, cocinero, nodriza, niñera, palafrenero, peón de labor y todo aquel que, viviendo en la casa, o fuera de ella, sirva 'mediante un salario en los quehaceres domésticos" "44.

Esta definición era más acotada que la anterior y tenía al menos dos aspectos que resultan de interés. Por un lado, la identificación del servicio doméstico con la prestación de un servicio privado y el desempeño de quehaceres domésticos en una casa, en la que se podía

${ }^{41}$ La Prensa, 25 de enero de 1888. Citado por Marotta, S., El movimiento sindical argentino. Su génesis y desarrollo, Op. Cit, p. 47.

$42 \mathrm{~A}$ los pocos días de su vigencia, una niñera francesa de quince años de edad fue obligada a realizar tareas ajenas a su función y a costear con su sueldo la limpieza de su delantal y de su cofia. Como ella se negó, la echaron y dejaron constancia del motivo de su despido en la libreta: "ha sido despedida por desobediente y por contestar con altanería". Marotta, S., El movimiento sindical argentino. Su génesis y desarrollo, Op. Cit, p. 47.

${ }^{43}$ El proyecto fue presentado el 23 de marzo de 1888 por los concejales Díaz, Pieres, Almeida, Cigorrarra, Rodríguez, Seeber y Ruiz. La información disponible no nos permite dilucidar si el proyecto fue presentado y nunca se trató o si fue sancionado y no pudo implementarse. Lo que sí es seguro es que también fracasó.

${ }^{44}$ Marotta, S., El movimiento sindical, argentino. Su génesis y desarrollo, Op. Cit, p. 47. El subrayado es nuestro. 
vivir o no. Por el otro, el énfasis en que se servía a cambio de un salario. Los elementos que prevalecieron al momento de delimitar las ocupaciones y actividades que serían comprendidas bajo la expresión "sirvientes" parecen haber sido en este caso: el espacio laboral (la casa); el tipo de trabajos ("servicios privados", "quehaceres domésticos"); y el carácter asalariado de los mismos ("por un salario"). De esta forma, quedaban por fuera finalmente los y las trabajadoras de comercio (mozos de hoteles, cafés, casas de comida, etc.) y los y las trabajadoras domésticas no remuneradas.

Por otra parte, el uso de la libreta dejaba de ser obligatorio. En todo caso, los y las sirvientes podían solicitarla para registrar el salario estipulado, las cantidades que se le darían "en abono" y los meses que les iban pagando. Dicha libreta debía ser completada por quien hiciera las veces de "dueño", pero ya no serían permitidas "anotaciones relativas a la conducta del sirviente". En todo caso, este último podía solicitar un certificado de su conducta durante su servicio al patrón ${ }^{45}$.

Frente a estas reformulaciones es posible pensar que, en la pulseada por la definición de los sentidos atribuidos a la expresión "sirvientes" y por las formas en que los mismos podían ser afectados por la normativa, fueron los y las trabajadoras quienes lograron imponer su razón. Es que parecen haber incidido en las modificaciones planteadas, las reiteradas resistencias que opusieron tanto quienes no aceptaban ser identificados como sirvientes como aquellos sirvientes que no querían someterse a un régimen que consideraban pernicioso y estigmatizante.

Hacia fines de siglo existía una percepción negativa del avance municipal en la regulación de esas relaciones laborales, la que era compartida por los y las trabajadoras considerados sirvientes pero también por los patrones. La intervención de las autoridades públicas era interpretada en términos de restricción de las libertades individuales: un atentado contra la libertad de contrato y de trabajo. A su vez, era considerada una forma de coerción y un agravio a la dignidad de los y las sirvientes.

A pesar de tratarse de un proyecto más flexible en su aplicación, y más conciliatorio con los intereses de los sujetos que serían por él alcanzados, también parece haber sido resistido por los diferentes gremios. En efecto, en el Digesto publicado en 1894 ya no se publicó

45 Entre otras cuestiones, el proyecto planteaba asimismo que el servicio podría contratarse por tiempo determinado pero en ningún caso por más de cinco años. Además, cuando no hubiera tiempo estipulado, establecía las pautas de ruptura del vínculo laboral. El sirviente no podía abandonar antes de los diez días su empleo y se le podían descontar hasta diez días de sueldo por abandonar su puesto "sin una causa grave". De lado del patrón, debía abonarle una suma igual en caso de despedirlo sin acordar el plazo señalado. Marotta, S., El movimiento sindical argentino. Su génesis y desarrollo, Op. Cit, p. 48. 
ninguna ordenanza que reglamentara el servicio doméstico, lo cual estaría indicando que fueron derogadas o que cayeron en desuso ${ }^{46}$.

Las tentativas regulatorias no cesaron y nuevos proyectos asomaron hacia el Centenario, aunque en un contexto diferente. Como veremos en el próximo apartado, una mayor predisposición a la intervención de las autoridades públicas se traducirá en reclamos concretos para que el municipio sancione nuevas reglamentaciones.

\section{Organizaciones que reclaman reglamentaciones}

La posibilidad de los y las trabajadoras de oponer sucesivas resistencias a ese poder municipal, en sus intentos de avanzar en la vigilancia y control de los sirvientes, debe leerse en el marco de un incremento generalizado de la conflictividad social asociada a la pobreza, el déficit habitacional, los problemas sanitarios, el aumento de la protesta obrera, las nuevas formas de organización y la difusión de corrientes ideológicas que desafiaron la validez de las instituciones políticas y económicas vigentes a fines del siglo XIX. A estos y otros fenómenos refieren los estudiosos y los propios contemporáneos cuando describen la emergencia de la cuestión social en nuestro país ${ }^{47}$.

Durante toda la década del ochenta se produjeron huelgas, la expresión más clara y visible del conflicto obrero-patronal. $\mathrm{Y}$ al tiempo que socialistas y anarquistas multiplicaban sus actividades en su afán de organizar y dirigir a los trabajadores, fueron surgiendo Sociedades de Resistencia, las organizaciones obreras más importantes vinculadas directamente al mundo del trabajo (aunque no las únicas). Distintos grupos de trabajadores reclamaban mejoras en los salarios, el establecimiento de una jornada "justa" y la readmisión de trabajadores despedidos como consecuencia de conflictos laborales ${ }^{48}$.

46 Esta ausencia de reglamentación en torno al servicio doméstico se reiteró en los Digestos publicados posteriormente, en los años 1894, 1898, 1904, 1907.

${ }^{47}$ La llamada "cuestión social" argentina se remonta a fines del siglo XIX y hace referencia a un conjunto de consecuencias no deseadas del aluvión inmigratorio, la urbanización y las transformaciones económicas y productivas. Esos procesos dieron lugar a una serie de problemas en materia de vivienda, salud y sanidad; fueron asociados al aumento de la criminalidad urbana, la prostitución, el alcoholismo pero así también, al surgimiento de las organizaciones obreras y de sus nuevas formas de protesta, a la irrupción de fuerzas político-ideológicas contestatarias y al creciente influjo del terrorismo anarquista. Zimmermann, Eduardo A., Los liberales reformistas. La cuestión social en la Argentina 1890-1916, Op. Cit., p. 11-13; Suriano, Juan, "Introducción”, en Suriano, Juan (comp.), La cuestión social en Argentina 1870-1943, Op. Cit.

48 En el último cuarto del siglo XIX, los trabajadores se organizaron en instituciones de distinto tipo: sociedades mutuales, cooperativas y ateneos populares, centros culturales. Las sociedades de ayuda mutua reunían a los miembros de una misma comunidad étnica-nacional y también a los trabajadores de un mismo oficio. Las sociedades gremiales y de resistencia surgieron de un proceso de diferenciación en el seno de las asociaciones mutuales por oficio. Aparecieron en la ciudad a fines de la década de 1870 y una década más tarde comenzaron a multiplicarse. Muchas de estas organizaciones estaban vinculadas a partidos o grupos políticos, aunque también estaban las que eran autónomas. Funcionaban bajo la responsabilidad y el impulso de un grupo de activistas y no 
A principios de 1890 la crisis económica y social se había agudizado tanto que había dado lugar a una fuerte ola de desempleo, al incremento de los precios de productos de primera necesidad y al de los alquileres. Y si en los años posteriores hubo una breve recuperación, antes del cambio de siglo aquellos males sociales retornaron ${ }^{49}$. El malestar estalló con crudeza al despuntar el novecientos, inaugurándose un ciclo de huelgas, boicots y manifestaciones que generaron preocupación entre las elites y las autoridades de gobierno. El problema obrero ya no se podía obviar.

"Las perturbaciones económicas y el malestar se hacen sentir en todos los gremios", señalaba La Prensa en un artículo de una serie de cuarenta que fueron publicados en el año 1901, con el propósito explícito de elaborar un informe "exhaustivo" de las condiciones de vida y trabajo de las clases laboriosas (lo que fue un fenómeno inusual dentro del periodismo de la época y que no puede disociarse de dicho contexto $)^{50}$.

Haciendo referencia a la coyuntura, un cronista indicaba que si bien había algunos grupos que no pertenecían propiamente a la "categoría del obrero", era igualmente interesante conocer su situación ${ }^{51}$. De allí que se detuviera en algunos "servidores de secundaria categoría", entre los que ubicaba a quienes se dedicaban al servicio doméstico. Señalaba que este gremio (conformado mayoritariamente por mujeres y niños), también sufría las consecuencias de la crisis, especialmente a causa del gran número de personas que "a falta de trabajo" se dedicaban a dicha actividad. El sector se había aumentado "con una masa de población sin pericia para el oficio" que, desplazada del campo de la industria, buscaba "en esa ocupación un medio de subsistencia" 52 . Por su parte, agregaba, las familias también participaban de las dificultades que presentaba el servicio, porque ellas (en tanto empleadoras) no podían satisfacer las exigencias del gremio debido a la decadencia de sus economías domésticas ${ }^{53}$. Todo esto, concluía, redundaba en una baja general de los sueldos de los sirvientes, que en ese momento marcaban un notable descenso en comparación con los que se pagaban años atrás.

contaban en general entre sus filas con funcionarios profesionales. Intentaban financiarse con las cuotas mensuales que abonaban los afiliados (aportes que eran en general muy irregulares) y muchas compartían el local con otras asociaciones afines. Lobato, M., "Los trabajadores en la era del progreso", Op. Cit., p. 489. Falcón, Ricardo, El mundo del trabajo urbano (1890-1914), CEAL, Buenos Aires, 1986, p. 83.

${ }^{49}$ Para entonces, el movimiento huelguístico había registrado un importante renacer. En el año 1896 eran 30 las sociedades de resistencia que accionaban en la ciudad (aunque muchas de ellas tenían vida efímera y sus actividades variaban considerablemente de acuerdo a los niveles de conflictividad y a coyunturas específicas). Falcón, R., El mundo del trabajo urbano (1890-1914), Op. Cit., p. 83.

${ }^{50}$ González, Ricardo, Gente y Sociedad. Los obreros y el trabajo. Buenos Aires, 1901, CEAL, Buenos Aires, 1984, p. 10.

51 "Revista de gremios. El exceso de personal. Perjuicios que causa. Los corredores, maestros y profesores, el servicio doméstico, empleados de correos y telégrafos", La Prensa (LP), 18 de septiembre de 1901. González, R., Gente y Sociedad, Op. Cit., p. 79-81.

52 Refería a "la desocupación de brazos jornaleros".

53 González, R., Gente y Sociedad, Op. Cit., p. 79-81. 
Fue en medio de esta crisis que se creó la "Liga Internacional de Domésticos", organización sindical de raigambre socialista que pretendió aglutinar a todos los sirvientes: mucamos, porteros, cocheros, cocineros ${ }^{54}$. En su declaración de principios, los portavoces de la flamante sociedad hicieron el siguiente diagnóstico sobre la situación de la domesticidad porteña:

“(...) Siendo las condiciones en que actúa el gremio de domésticos malísima en su forma económica, moral y social, que los sujeta a una vida de imposiciones que denigran a la persona, privándolos de la familia, la libertad y de toda actuación en la sociedad de la cual forman parte, y siendo las causas de ese malestar del gremio su indiferencia y despreocupación de su propio estado y en esencial la competencia que los mismos domésticos se hacen entre sí, La Liga Internacional de Domésticos, representada en asamblea por los miembros que la componen, declara:

Que, o el gremio de domésticos continúa desunido haciéndose la competencia, que determinará necesariamente su empeoramiento progresivo hasta un estado inaguantable y humillante dentro de la actual civilización, o se organiza en sociedad gremial para conseguir la unión de la mayoría de los domésticos de ambos sexos, a fin de implantar la 'instrucción, protección y mejoramiento' en el gremio, con lo que se pondrá dique a la tendencia de empeoramiento y se conquistarán condiciones de vida más humanas, justas y equitativas ${ }^{55 \%}$.

El planteo era claro: el problema de los sirvientes era que aún no se habían organizado en defensa de sus intereses. La Vanguardia, órgano de prensa del Partido Socialista, se complació en anunciar el movimiento de organización emprendido por un gremio tan "importante y meritorio" como el de los domésticos de la capital, quienes habían constituido una "poderosa asociación" para mejorar sus condiciones del trabajo ${ }^{56}$.

\footnotetext{
${ }^{54} \mathrm{La}$ organización fue creada el 12 de mayo de 1901. Celebró su primera asamblea el $1^{\circ}$ de junio de ese mismo año con una asistencia de 150 asociados y fue presidida en ese entonces por Felipe Gauna. En adelante, la comisión directiva se reuniría trimestralmente, los días domingo por la tarde, en el local social de la calle Paraguay 856, por donde desfilaron figuras como Alfredo Palacios, Gino Alfredo Cartei, Marcelino Blanco, para disertar sobre la necesidad de la organización de esos trabajadores y las grandes ventajas que conseguirían quienes pertenecieran al gremio. Un tiempo después se mudaron a un local más amplio en la calle Córdoba 1030, que compartieron con la "Unión Cocheros". A principios de 1905 se trasladaron a Florida 777, donde funcionaba la Cámara de Trabajo, pero a los pocos meses trasladaron su secretaría a la calle Santa Fé 1125. La Liga estuvo conformada por "socios" y "socias" desde sus comienzos. La "sección domésticas" estuvo presidida en sus orígenes por Plácida Cardó de Varela, y aunque durante los primeros tiempos varones y mujeres sesionaban de forma separada, a los pocos meses de su creación comenzaron a trabajar de forma conjunta. Información extraída de La Vanguardia (LV), consultada en sus publicaciones fechadas de 17 de agosto de 1901, 21 de septiembre de 1901, 19 de septiembre de 1903, 2 de octubre de 1927, 28 de enero de 1905 y 5 de agosto de 1905.

${ }^{55} L V, 2$ de octubre de 1927.

${ }^{56} L V, 21$ de septiembre de 1901.
} 
La Liga se pósicionó rápidamente en el escenario político y social. En marzo de 1903 participó junto a otras cuarenta sociedades de resistencia del país en la fundación de la Unión General de Trabajadores, y Felipe Gauna, quien fuera su presidente, formó parte de la primera junta ejecutiva nacional ${ }^{57}$. Su desenvolvimiento no distó demasiado de la experiencia de otras sociedades de resistencia que existieron en aquellos años. Desde sus primeros tiempos se planteó la necesidad de avanzar en una serie de iniciativas para vigorizar su movimiento organizativo. Cobró vida a partir de la sanción de un estatuto, la celebración periódica de asambleas y la elección de una comisión directiva. Intentó ampliar su campo de acción a partir de la creación de una oficina de trabajo, una caja de socorros, una biblioteca social, una escuela para los socios y sus hijos y un periódico para la defensa de los intereses del gremio ${ }^{58}$. Asimismo, intentó ampliar la participación de los domésticos de la ciudad a partir de la realización de distintos eventos recreativos y sociales que difundían y comentaban en la prensa -conferencias, bailes familiares, rifas, matinées ${ }^{59}$.

La Sociedad resistió el paso de los años y sus iniciativas corrieron distinta suerte ${ }^{60}$. La imagen que nos devuelven las fuentes es que más allá del puñado de activistas y asociados que le daban impulso, esta organización no parece haber tenido demasiado influjo entre los trabajadores domésticos de la ciudad. Si en 1901 eran ciento cincuenta los asociados, una

57 La UGT fue conformada por el Partido Socialista en 1903, después de abandonar la Federación Obrera Argentina (FOA) -organización que había creado junto a los anarquistas en 1901 y que quedó en manos de estos últimos, convirtiéndose en la Federación Obrera Regional Argentina (FORA) a partir de 1904. Véase: Marotta, S., El movimiento sindical argentino. Su génesis y desarrollo, Op. Cit., p. 129-132; Iscaro Rubens, Historia del movimiento sindical, Editorial Ciencias del Hombre, Buenos Aires, 1974, p. 112; Lobato, M., "Los trabajadores en la era del progreso", Op. Cit., p. 491.

58 Según consta en las fuentes, el $1^{\circ}$ de junio de 1902 se lanzó un periódico mensual Unión del Doméstico, cuya redacción estuvo a cargo de F. Figueredo, uno de los asociados. Como la propaganda constituía una preocupación central de la sociedad, la función de la publicación era dar a conocer a los trabajadores las acciones desplegadas. $L V, 24$ de mayo de 1902. No hemos podido acceder a esta publicación aún porque sus ejemplares se encuentran en el Instituto de Historia Social de Amsterdam (ISH).

59 “(...) La velada celebrada por esta sociedad en los salones del Orfeón Gallego, resultó muy concurrida (...) La fiesta terminó en medio de la mayor fraternidad y compañía (...)", $L V, 10$ de mayo de 1902; "Liga Internacional de domésticos celebrará un matinée el domingo 5 de julio en los salones del Orfeón Argentino (...)", $L V, 27$ de junio de 1903; “(...) el sábado 2 de noviembre, celebrará una función, conferencia y baile familiar, en el Salón Ciclista, calle Suipacha 444”, LV, 8 de octubre de 1904; “(...) Gran función, conferencia y baile hoy sábado á las 9:30 de la noche, en el Salón de la Cámara de Trabajo, Florida 777, conmemorando el $4^{\circ}$ aniversario de su fundación y á beneficio de la caja de socorros mutuos. Programa: $1^{\circ} \mathrm{A}$ través de la vida, drama en tres actos, de Luis Pesce.- $2^{\circ}$, conferencia por el comp. A. L. Palacios.- $3^{\circ}$, gran baile.- $4^{\circ}$, rifa. Entrada, $\$ 1$; mujeres, gratis; asiento, 20 centavos. No se suspenderá por mal tiempo", $L V, 13$ de mayo de 1905.

${ }^{60}$ En sus comienzos creó una oficina de trabajo atendida por un regente a sueldo, organizó una biblioteca social, sostuvo por unos años la publicación gremial antes mencionada y creó en 1913 una caja de socorros mutuos con un fondo en caja de unos 20 mil pesos m/n. LV, 2 de octubre de 1927. De todas formas parece haber atravesado por momentos difíciles, ya que se mudaban frecuentemente de local y a veces compartían el espacio con otras sociedades, mientras se esforzaban por juntar dinero para comprar un local propio. $L V, 5$ de agosto de 1905. 
década más tarde no juntaban mil. Y si bien frente a la desaparición de muchas otras sociedades es notable que ésta haya persistido, aumentando además su número de afiliados, no es menos cierto que en torno al Centenario los sirvientes sumaban alrededor 100 mil en la ciudad, y por lo tanto su alcance era limitado ${ }^{61}$.

Si hubo algo que concentró la atención de los miembros de esta asociación desde un primer momento fue a la lucha contra las agencias de colocación. Desde su fundación sostuvieron una activa campaña de agitación contra esas "casas indeseables". Sus portavoces condenaron enérgicamente su existencia, catalogando a estos comercios de "verdaderos centros de explotación de la ignorancia y la miseria del pobre", y a los agencieros de "plaga", "zánganos", "comerciantes indecentes", "aves de rapiña". Manifestaban que era una vergüenza que una nación "civilizada" no contara con "oficinas de trabajo" que no atentaran contra el trabajador, y batallaban tanto por la desaparición de las agencias privadas como por la creación de una Bolsa de Trabajo que estuviera subvencionada por el municipio ${ }^{62}$.

Frente a la proliferación de estas casas, la Liga acudió a diversas estrategias para avanzar, si no en su abolición, al menos en su reglamentación. Presentó ante la municipalidad solicitudes para que regularan su funcionamiento y realizó campañas para juntar firmas entre los patrones para exigir su prohibición ${ }^{63}$. Formó, junto a una veintena de sociedades de resistencia, un comité para realizar un "gran mítin", exigiendo a las autoridades públicas la regulación de las mismas (y según hizo constar La Vanguardia, resultó ser un "acto numeroso", ya que había contado con la cooperación de la UGT y el Partido Socialista) ${ }^{64}$. Además de estas acciones colectivas, organizó en varias oportunidades conferencias, lanzó

${ }^{61}$ De todas formas, como ha señalado Falcón, hay que considerar también que generalmente el número de socios no reflejaba el peso real de las sociedades, ya que en ciertas ocasiones, las organizaciones revelaban una capacidad de convocatoria mucho más amplia, atrayendo a muchos trabajadores no sindicalizados. Por otra parte, también es cierto que, debido a su carácter predominantemente combativo, estas sociedades no generaban una participación constante y que en general tuvieron un papel muy reducido como centros de integración social y política de los trabajadores (ya que además, en ese campo de acción, competían con otro tipo de organizaciones mutuales y recreativas, las que fueron levantadas por comunidades nacionales extranjeras). Falcón, R., El mundo del trabajo urbano (1890-1914), Op. Cit., p. $88-89$ y p. 96.

${ }^{62} \mathrm{LV}, 30$ de noviembre de 1901. Este reclamo no fue privativo de la Liga. En realidad, el movimiento obrero tuvo desde muy temprano una reiterada preocupación por el tema. Ya en 1892, había sido presentado sin éxito un proyecto en el Concejo Deliberante de la ciudad, para que se creara una Bolsa de Trabajo. La batalla contra los intermediarios y las agencias de colocación continuó durante mucho tiempo, y en casi todos los congresos obreros (sobre todo los convocados por la UGT), se retomaban los ataques contra las agencias al mismo tiempo que se sucedían las tentativas de constitución de una Bolsa de Trabajo. Falcón, R., El mundo del trabajo urbano (1890-1914), Op. Cit., p. 66-72.

63 "Las agencias y la Liga de domésticos", LV, 8 de marzo de 1902; LV , 14 de febrero de 1903.

${ }^{64}$ Por su intermedio se elevó a los poderes públicos una solicitud pidiendo la aplicación de una fuerte patente a las agencias de colocaciones. $L V, 19$ de septiembre de 1903. 
"manifiestos" en su contra y publicó artículos alusivos al tema ${ }^{65}$. Por último, como ya mencionamos, creó una oficina de trabajo para facilitar personal "competente", sin cobrar comisión ni a patrones ni a trabajadores ${ }^{66}$.

¿Por qué tanto ensañamiento con las agencias de colocación? ¿Qué se jugaba en esa cruzada? Para responder a esta pregunta debemos atender una vez más al marco de acción general en el que la Liga se desenvolvía.

Las agencias de colocación operaban como intermediarias, facilitando el contacto entre la oferta y demanda de trabajo. A cambio de la búsqueda y colocación cobraban una comisión que era, por cierto, la principal fuente de su rentabilidad. En general a los trabajadores les cobraban por adelantado, no así a los patrones. Esto daba lugar a abusos de todo tipo. Quienes buscaban empleo eran objeto de frecuentes estafas y mentiras.

Las organizaciones patronales y obreras entablaron una verdadera lucha en torno al reclutamiento de trabajadores. Para los sindicatos estaba en juego la posibilidad de tener a su disposición un agente de reclutamiento y de acercamiento de los trabajadores a los gremios (de captación), pero también buscaban una herramienta de presión para hacer frente a la patronal ${ }^{67}$. Las agencias estuvieron en el centro de la disputa con las sociedades gremiales y de resistencia porque habían experimentado de forma temprana una importante expansión. En los seis años que transcurrieron entre 1906 y 1912 estas casas tuvieron un influjo cada vez mayor sobre el mercado de trabajo porteño, triplicándose su número y sextuplicando la cantidad de colocaciones por ellas efectuadas ${ }^{68}$. En el caso del servicio doméstico, las agencias estuvieron entre los canales de acceso más importantes al sector ${ }^{69}$.

65 "Esta sociedad ha resuelto dirigir un manifiesto al pueblo contra los perjuicios y abusos que originan las agencias de colocaciones y falsas sociedades de protección". LV, 26 de marzo de 1904. Véanse asimismo, acciones difundidas en $L V, 8$ de octubre de 1904 y LV, 24 de diciembre de 1904.

${ }^{66} \mathrm{LV}, 11$ de junio de 1904.

${ }^{67}$ Además, la cuestión del control del empleo tenía ese otro trasfondo que era la cuestión del reconocimiento del derecho de los sindicatos, por parte de las asociaciones patronales, y la posibilidad de establecer relaciones cotidianas de negociación. Entablar esas negociaciones era reconocer de hecho la participación de los sindicatos en la organización del trabajo. Falcón, R., El mundo del trabajo urbano (1890-1914), Op. Cit., p. 66-72.

${ }^{68}$ El número de agencias registradas por el DNT fueron 14 en 1906, 20 en 1909 y 50 en 1912, y la cantidad de colocaciones por ellas efectuadas fueron más de 24 mil setecientas, mas de 69 mil setecientas y 171 mil doscientas, respectivamente. Véase República Argentina, Boletín del Departamento Nacional del Trabajo, n²4, $1^{\circ}$ de agosto de 1913, Imprenta "Alsina", Buenos Aires, 1913, p. 501.

${ }^{69}$ El DNT contabilizó en 1906 la existencia de catorce agencias que habían procurado trabajo a 24.755 personas. Había ocho que se dedicaban específicamente al servicio doméstico, cinco que operaban con toda clase de trabajos y una que tomaba amas de leche únicamente. Las colocaciones para el servicio doméstico representaron en ese año al menos el 40\% del total. En el año 1912 el número de agencias particulares prácticamente se cuadruplicó y efectuaron unas 171.294 colocaciones. De las cincuenta casas registradas en la ciudad, la mitad se especializaban en el servicio doméstico. Según los informes, consiguieron empleo para más de 41 mil sirvientes, esto es, realizaron más de cien colocaciones diarias. Es importante aclarar que los datos ofrecidos sólo contabilizan las colocaciones 
Frente a semejante avanzada, es comprensible que fueran objeto de alarma para las sociedades gremiales y las autoridades públicas, sobre todo si consideramos la mala prensa de la que gozaban en aquellos años. Y aunque esas organizaciones intentaron contrarrestar el influjo de las agencias privadas con la creación de cámaras y bolsas de trabajo bajo control obrero, su eficacia parece haber sido muy limitada ${ }^{70}$.

Por otra parte, desde su creación en 1907, el Departamento Nacional del Trabajo (DNT) no sólo comenzó a elaborar informes sobre las agencias particulares emplazadas en la ciudad, sino que a su vez intentó zanjar el problema de aquellos trabajadores por ellas enganchados, confeccionando listas en las cuales se inscribían los desocupados para ser colocados gratuitamente ${ }^{71}$. Ahora bien, si durante sus primeros años este organismo sólo pudo solicitar información a las agencias, a partir de 1912 sus atribuciones se ampliaron con la sanción de la Ley Orgánica del DNT72. Fue así que, en el año 1913, la "División Inspección" de este organismo elaboró un informe en el que dejaba constancia de la existencia de una treintena de agencias que actuaban en contravención con las disposiciones vigentes, solicitando al poder municipal que tomara riendas en el asunto.

Así pues, el escenario a principios de siglo XX es otro. El avance del movimiento obrero y del reformismo social dio lugar a un cambio en la percepción del rol del Estado y a la convalidación (no sin resistencias) de su intervención en las relaciones obrero-patronales ${ }^{73}$. Y si por un lado, las autoridades de gobierno intentaron dar respuestas y aplacar las tensiones, por el otro, apuntaron a integrar a los trabajadores al sistema con una estrategia que combinó

de las agencias especializadas en el rubro. Quedan fuera, entonces, las colocaciones para el servicio doméstico que fueron realizadas por otras agencias (generales), por no poder diferenciarlas de aquellas efectuadas para otro tipo de trabajos. República Argentina, Boletín del Departamento Nacional del Trabajo, n²7, $1^{\circ}$ degosto de 1913, Imprenta "Alsina", Buenos Aires, 1913, p. 497.

70 En efecto, mientras en 1912 las agencias particulares habían conseguido empleo para más de 171 mil trabajadores, las sociedades gremiales habían efectuado unas 19 mil colocaciones (tan sólo una novena parte). República Argentina, Boletín, p. 501-505.

${ }^{71}$ Falcón, R., El mundo del trabajo urbano (1890-1914), Op. Cit., p. 71.

72 La Ley 8.999, del 8 de octubre de 1912, estableció en su artículo $5^{\circ}$ el marco para la creación de un Registro de colocaciones para obreros, y le otorgó la facultad de inspección de las agencias particulares existentes.

73 El gobierno nacional convocó a una serie de "expertos" y estudiosos, de diversas alineaciones políticas e ideológicas, para que produjeran un diagnóstico sobre la cuestión social y para que analizaran las soluciones adoptadas en otros países, como antecedentes para el diseño de un proyecto que sería presentado en el Congreso de la Nación. El proyecto de Ley Nacional del Trabajo de 1904 fue un ambicioso antecedente en la regulación de las relaciones laborales y del conflicto social, aunque nunca fue sancionado por las resistencias que despertó, por abarcar una gran diversidad de temas y por resultar demasiado complejo. Sería mucho más sencillo proponer reformas parciales y específicas en forma gradual. En efecto, luego de este intento frustrado, varios proyectos de menor envergadura se desprendieron del Código de Joaquín V. González y comenzaron a ser sancionados (la ley de descanso dominical, la reglamentaria del trabajo de mujeres y niños, la de accidentes de trabajo, entre otras). Véase: Panettieri, José, Las primeras leyes obreras, CEAL, Buenos Aires, 1984, p. 11-18; Zimmermann, E., Los liberales reformistas. La cuestión social en la Argentina 1890-1916, Op. Cit., p. 178; Suriano, J., La cuestión social en Argentina 1870-1943, Op. Cit. 
la coerción y el consenso. De esta forma, el Estado comenzó a involucrarse y a mediar en aquellas relaciones. Entre otras cuestiones, el poder legislativo comenzó a tratar el problema del trabajo y su regulación. Desde distintos frentes, socialistas, liberales reformistas y católicos sociales (no así los anarquistas) promovieron la confección de leyes de protección laboral. Las condiciones de vida y de trabajo de los sectores populares no sólo se hicieron visibles, sino que pasaron a integrar la agenda pública. Veamos entonces qué sucedió con el tratamiento del servicio doméstico en este contexto.

\section{Nuevas reglamentaciones con viejos objetivos}

En el marco de aquellas campañas de denuncia y visibilización del problema de las agencias de colocaciones, el Concejo Deliberante de la ciudad volvió a insistir en la reglamentación del servicio doméstico. El tema que más controversias generó, y en el que en adelante se centraron los esfuerzos reglamentarios, fue justamente el de las agencias particulares. Hasta ese momento se las había intentado controlar a partir del establecimiento de habilitaciones, pautas de funcionamiento, instrucciones para recabar información sobre los sujetos que colocaban o multas. En 1898 se sancionó una ordenanza que regulaba su actividad. En 1908 una nueva reglamentación detalló las condiciones que debían reunir los locales donde se ubicaban, e intentó controlar los usos alternativos que, se sospechaba, podían darles a los mismos. Estableció que las agencias no podían habilitarse sin un permiso municipal, que debían llevar un registro tipificado de quienes obtuvieran colocación por su intermedio e implementó el uso de una "boleta", que debían entregar a los y las trabajadoras ${ }^{74}$.

Lo que interesa resaltar es que, en el transcurso de un año, en el Concejo Deliberante se presentaron tres proyectos para reglamentar el servicio doméstico. A fines de 1911, el Sr. Zolezzi, propuso que toda persona que se dedicara al servicio doméstico tendría que estar provista de una "carta de identidad", expedida por una dependencia municipal75. Explicitaba

\footnotetext{
${ }^{74}$ En el marco de la discusión del proyecto de esta ordenanza, uno de los concejales intervino para proponer la sustitución de la "boleta" por el uso de una "libreta", porque era lo más común. Argumentaba que esta última era más adecuada en caso de tener que intervenir la policía o los jueces para alguna investigación "por mal comportamiento ó cualquier delito, cometidos por uno de estos individuos ó individuas". Esto se debía a que en la libreta quedaba también el registro donde constaban los antecedentes, "porque la boleta significa una tarjeta, mientras que en la libreta constarían todas las anotaciones". Proyecto presentado por el Sr. Concejal Dr. Coll, discutido en la sesión ordinaria del 20 de octubre de 1908. República Argentina, Versiones Taquigráficas de las Sesiones del Concejo Deliberante de la ciudad de Buenos Aires correspondiente al $2^{\circ}$ período de 1908, Imprenta de M. Biedma é Hijo, Buenos Aires, 1908.

${ }^{75}$ En la carta constaría su filiación y su último domicilio. Para controlar su autenticidad, debería estar firmada por un funcionario designado a tales efectos, y llevaría una estampilla municipal de 0,50 centavos, que habría que reponer cada 6 meses. Honorable Concejo Deliberante, Versión Taquigráfica de la continuación de la $5^{\circ}$ sesión de prórroga del $2^{\circ}$ período, 30 de diciembre de 1911.
} 
asimismo que el patrón ya no tendría derecho a reseñar en ella "nada sobre la mala conducta del doméstico despedido", sino que sólo haría constar los días de su admisión y despido. Por último, establecía la entrega de "premios en dinero y medallas honoríficas" a aquellos sirvientes que se distinguieran "por la fidelidad a sus amos, por actos de abnegación, de honradez y de cariño hacia los niños".

Como se desprende de lo antedicho, si bien este concejal insistió en la posibilidad de implementar un registro especial para sirvientes y una suerte de libreta ("carta de identidad"), a su vez intentó evitar la discrecionalidad que podían tener los patrones si se les permitía asentar las consideraciones sobre aquellos que dejaban su servicio. Además, en vez de poner el acento en identificar a los malos sirvientes, su intención fue destacar positivamente a los que tenían buen desempeño.

Cinco meses más tarde, evocando la Ley Orgánica Municipal de 1880, el Sr. Sylla Monsegur retomó el tema de la reglamentación". Propuso la creación de un "registro especial" y que los y las sirvientes portaran una "libreta de identidad"77. Argumentó que su implementación no debía provocar dificultades porque desde el más potentado hasta el más pobre llevaba en su bolsillo algún documento que lo identificaba. Por lo demás, habiendo sido reglamentadas ya en otros oficios (se refería a la libreta de identidad, a la fotografía, a las impresiones digitales), señalaba que no era posible que profesiones "tan serias e importantes", como ésa, pudiera provocar resistencias.

Este concejal intentó a su vez avanzar en la "municipalización" de las agencias de colocaciones y en la prohibición de las casas bajo dominio privado. Consideraba que había que evitar su existencia, debido a que estas últimas no daban garantías a los patrones respecto de las condiciones de "moralidad y competencia" que debía tener el servicio que recomendaban. Estas casas se guiaban por el lucro y sólo se interesaban por incrementar el número de colocaciones ${ }^{78}$.

\footnotetext{
${ }^{76}$ República Argentina (RA), Versiones Taquigráficas (VT), $1^{\circ}$ periodo de 1912 (1912), Buenos Aires, 1919, p. 258.

77 El registro sería obligatorio y se les daba un plazo de un año para regularizar su situación. En esa primera instancia se les extendería gratuitamente una "libreta de identidad" la que, por cierto, guardaría cuantiosa información. Los datos apuntados serían: a) nacionalidad, edad, antecedentes genealógicos y, si era extranjero, años de estadía en el país; b) firma, y si no lo sabe hacer, la constancia de esa particularidad; c) fotografía; d) antecedentes profesionales; e) especialidad; f) una planilla dividida en casillas, en las que se anotaría el nombre de las familias que había servido, cambios de servicio y la fecha de los mismos; g) una planilla igualmente dividida en casillas, con los siguientes títulos: honradez, competencia, laboriosidad, y el espacio necesario para el informe de los patrones; h) una planilla con el título de observaciones, para poder ampliar dichos informes si se consideraba conveniente. RA, VT, 1912, p. 258.

${ }^{78} \mathrm{El}$ proyecto establecía que quedarían prohibidas las agencias de colocaciones para el servicio doméstico bajo pena de multa de 500 pesos. Proponía la creación de un "Registro de servicio doméstico" y de sub-sedes, donde se recibirían los ofrecimientos y pedidos de servicio que inmediatamente serían retransmitidos a la oficina central. Ésta confeccionaría varios registros de sus actividades y de los sirvientes que colocaba (artículos $5^{\circ}$ a $7^{\circ}$ ). Quienes
} 
Monsegur fundaba su propuesta en un estudio comparado de la legislación europea, donde la mayor parte de los países había tratado dicho fenómeno. En Francia se habían organizado oficinas municipales de colocación que eran gratuitas y estaban bajo la dirección de comisiones conformadas por personas "distinguidas" de las parroquias. En otros casos, la función de mediar entre la oferta y la demanda de trabajo estaba a cargo de corporaciones gremiales. Explicaba que, de todas formas, en Europa se había abordado el asunto desde el punto de vista del obrero, "no teniendo en cuenta para nada al patrón". Esto se debía a que en el viejo continente ese gremio era "más culto y más educado" que el nuestro, que se había formado entre los inmigrantes que llegaban al país "sin conocimientos de ninguna especie" e iniciaban su vida en América insertándose en el servicio doméstico. Frente a este panorama, no recomendaba dejar en manos de los sirvientes la organización del mercado de trabajo.

Como observamos, la caracterización que hacía de las agencias no distaba mucho de la que realizaba la Liga y, en definitiva, ambos querían su prohibición. La diferencia estribaba en los intereses que defendían (de patrones y sirvientes, respectivamente). Además, mientras uno bregaba por la creación de oficinas municipales, el otro luchaba por la creación de una Bolsa de Trabajo que estuviera bajo su control.

El concejal reconocía que su proyecto seguramente no sería bien recibido entre los sirvientes, sobre todo si se consideraba que en ese momento, a su entender, reinaba un espíritu en el que todas las iniciativas debían beneficiar al trabajador ${ }^{79}$. Este representante del poder municipal se declaraba abiertamente en favor de la patronal (aunque insistía con que sus medidas también beneficiarían a los sirvientes "honestos"). En un artículo publicado en Caras y Caretas, explicó su pensamiento sobre el asunto:

quisieran anotarse en la oficina municipal, deberían presentar una solicitud (con una estampilla municipal de 0,50 centavos $\mathrm{m} / \mathrm{n}$ ) junto a algún comprobante de identidad, un justificativo de "buena conducta y honorabilidad" o cualquier otro documento que sirva como antecedente para formar su foja de servicio; también se admitía la declaración de dos testigos de reconocida honorabilidad, para certificar la información facilitada por el sirviente (artículos $8^{\circ}$ a $11^{\circ}$ ). Deberían presentar con cada solicitud de empleo, la "libreta de identidad". Del lado de los patrones, se les exigía que el pedido lo formularan por escrito y que abonaran una estampilla municipal de 2 pesos $\mathrm{m} / \mathrm{n}$. Esa contribución sólo se renovaría después de pasados diez días de haber recibido al doméstico. Dentro ese lapso el solicitante podría efectuar todos los cambios de servicio que desease (siempre que fuera dentro de la misma especialidad). Vencidos los plazos, debería presentar nueva solicitud y abonar otra vez el derecho correspondiente. Esos mismos términos también se aplicaban a los domésticos. Además, cuando dejaban su colocación (o eran despedidos), deberían detallarlo en su libreta y en las planillas correspondientes. Y si se comprobaba que el patrón se negaba a cumplir con ese requisito o que sus informes no eran "la expresión de la verdad", podría ser multado con 500 pesos. RA, VT, 1912, p. 258.

79 "Comprendo que este proyecto no puede ser simpático para una parte de la población, porque dado el medio ambiente y el espiritu que reina boy en día, todas las iniciativas deben ser a beneficio del trabajador, toda medida que beneficie al patrón no puede considerarse con ese ambiente de simpatía del caso contrario; pero, es necesario tener en cuenta que la mayor parte de la población de Buenos Aires, con excepción de la obrera que vive en casas de inquilinato o conventillos, tienen sirvientes a disposición; por consiguiente, está interesada la mayor parte de la población de Buenos Aires en que se reglamente el servicio doméstico." RA, VT, 1912, p. 259-260. El subrayado es nuestro. 
“(...) Todo el mundo está convencido de la necesidad de reglamentar el servicio doméstico. Esta necesidad surge de las malas condiciones o, en otros términos, de las escasas garantías que a los patrones ofrecen las personas que se dedican a esta clase de labores y que están llamadas a vivir en trato continuo con sus amos y a participar de las diversas modalidades de la vida íntima del hogar.

En mi concepto $(. .$.$) esa reglamentación beneficiaría enormemente al trabajador honesto$ quien, presentando sus diplomas de competencia y honorabilidad, gozaría de mayor consideración, confianza y estima en el seno de las familias. Una de las consecuencias de todo esto sería sin duda alguna una mayor remuneración de sus servicios. Estoy convencido pues, de que mi proyecto redunda tanto en beneficio del patrono como del trabajador ${ }^{80,}$.

El redactor de la revista hacía notar que el proyecto estaba "excelentemente inspirado" y que no tenía duda de que de ser aprobado se pondría fin a un estado de cosas que perjudicaba tanto a los "señores" como a la "servidumbre". A los primeros, explicaba, "en sus intereses y seguridad personal". A los segundos, en "el buen concepto" que siempre debía rodearla (ya que, por carecer de reglamentación, la crónica policial había tenido que registrar hechos delictuosos contra los que se habían alzado tanto patrones como sirvientes).

En las voces que intervinieron en ese artículo subyacía la idea de que el servicio doméstico era un gremio "honrado y honesto", y que si aparecía vinculado al mundo del delito era porque se colaban en él "elementos malsanos", que manchaban su buen nombre. Lo que sobrevuela en estas reflexiones es el problema de la seguridad de los patrones y la permanente preocupación por determinar mejor quiénes eran estos sirvientes, cuáles sus antecedentes, cómo fueron sus trayectorias, cuáles sus movimientos.

Esta preocupación por identificar y controlar a los sirvientes era una expresión más de las ansiedades que generaba el aumento del crimen urbano, otra de las manifestaciones adversas de la modernidad. Como ha señalado Caimari, este fenómeno se comprende mejor si se considera que, desde la prensa, las estadísticas oficiales, los discursos políticos, los informes médicos, se había instalado la idea de que la ciudad se había vuelto más compleja e insegura. Claramente, estas expresiones se fundaban en un aumento efectivo de la criminalidad (sobre todo de los delitos contra la propiedad) ${ }^{81}$. El anonimato que Buenos

80 "El servicio doméstico en Buenos Aires", en CC, $\mathrm{n}^{\circ} 715$, junio de 1912.

${ }^{81}$ En 1880, la tasa de arresto de Buenos Aires arrojaba cifras impactantes (en 1885, alcanzaron 1 arresto por cada 9 residentes). Había una gran preocupación por el desorden urbano. No sólo crecía el número de arrestos, sino también el número de denuncias, sobre todo de delitos contra la propiedad. El aumento de los arrestos por delitos contra la propiedad constituía una tendencia claramente identificable: si en 1885 se registraron 25 robos por 10 mil personas, en 1915, la proporción trepó a 58. Lo que seguramente resultaba más alarmante, era que la tasa de detenidos por crimen cometido descendía notablemente durante ese mismo período. La policía iba muy por detrás de la demanda social de control. Caimari, Lila, Apenas un delincuente. Crimen, castigo y cultura en la Argentina, 1880-1955, Siglo XXI Editores, Buenos Aires, 2004, p. 75-85. Véase asimismo, García Ferrari, Mercedes, “'Una marca peor 
Aires ofrecía no sólo aumentaba el número de ladrones y rateros, sino que además, ofrecía oportunidades para nuevos criminales. La incertidumbre y el miedo a la "simulación" invadían las interacciones más cotidianas y alcanzaban la intimidad de los hogares. El servicio doméstico fue objeto de preocupación y conversación permanente, ya que se lo consideraba el campo de acción por excelencia de ladrones y ladronas, sobre todo de "entregadores" en connivencia con "scruchantes" 82.

Ahora bien, si Monsegur condensó en gran medida estas preocupaciones y se constituyó en un portavoz de los intereses de los patrones, Aguilar ofreció una perspectiva distinta, intentando equilibrar la balanza en favor de los sirvientes. A diferencia de los proyectos precedentes, no proponía la implementación de registros ni libretas especiales ${ }^{83}$. Sí planteaba la necesidad de modificar la reglamentación vigente para mejorar el control y funcionamiento de las agencias de colocación ${ }^{84}$. Como novedad, avanzaba en la regulación de otras

que el fuego'. Los cocheros de la Ciudad de Buenos Aires y la resistencia al retrato de identificación", en Caimari, Lila (comp.), La ley de los profanos. Delito, justicia y cultura en Buenos Aires (1880-1940), Fondo de Cultura Económica, Buenos Aires, 2007; de la misma autora, Ladrones Conocidos / Sospechosos reservados. Identificación policial en Buenos Aires, 1880-1915, Prometeo Libros, Buenos Aires, 2010.

${ }^{82}$ De Veyga, Francisco, "Los auxiliares del vicio y del delito", Archivos de Psiquiatría, Criminología y Ciencias Afines, 1904, p. 289-313; Rossi, José G., "Profesiones peligrosas. El servicio doméstico", Archivos de Psiquiatría, Criminología y Ciencias Afines, 1907, p. 72-77; "Medios empleados por los ladrones en la ejecución de los delitos. Entregadores", Revista de policía. Periódico quincenal. Órgano de los intereses generales de la institución policial, año XXI, Buenos Aires, octubre 16 de $1918, n^{\circ} 488$, p. 457-458.

83 Sólo se exigiría la cédula de identidad otorgada por la policía de la ciudad de Buenos Aires, de lo contrario, no se daría curso a ninguna demanda por salarios o cualquier otro conflicto originado en el vínculo laboral (artículos $1^{\circ}$ a $3^{\circ}$ ). "Proyecto de ordenanza reglamentaria del servicio doméstico", República Argentina, Versiones Taquigráficas, $2^{\circ}$ periodo de 1912, p. 867.

${ }^{84}$ Establecía la prohibición de que las agencias operaran sin habilitación y la obligación de ceñirse a la normativa (de lo contrario serían penalizadas con altas multas y, llegado el caso, clausuradas e inhabilitados sus titulares). Creaba impuestos dependiendo de su ubicación geográfica. Exigía a sus titulares y a sus empleados presentar cédula de identidad, un certificado de "intachable moralidad" (firmada por dos personas "distinguidas") y certificados de salud de forma periódica. En línea con la ordenanza de 1908, pautaba también las características que debían reunir los locales que ocupaban. No podrían ubicarse en sótanos y tendrían un mínimo establecido en cuanto al tamaño y el número de habitaciones (las que, por cierto, deberían ser luminosas y ventiladas). Deberían contar con una sala de espera para mujeres y otra para varones, en las que se prohibía la venta de bebidas alcohólicas, billetes de lotería, etc. Si la casa era más amplia, se insistía en que estas habitaciones no podrían tener comunicación con otras (para control del ejercicio clandestino de la prostitución). Se detenía a su vez en detalles tales como el revestimiento de las paredes, las características de los pisos y de los baños, las saliveras, la limpieza de los espacios y los artefactos, etc. (artículos $4^{\circ}$ y $5^{\circ}$ ). En relación al funcionamiento de estas casas, pautaba la implementación de dos registros: un libro de demanda y otro de oferta. Sus páginas serían rubricadas por un funcionario municipal, tendrían un número de orden y no podrían desecharse sin previa justificación. El "libro de la oferta" debería consignar: nombre y apellido del sirviente, edad, nacionalidad, número de la cédula de identidad, familias y domicilios de éstas donde había servido y tiempo que prestó servicios en cada casa. En las inscripciones de la demanda se haría constar: nacionalidad de la familia, cuántas personas, clase de servicio y sueldo que abonaría (artículo $6^{\circ}$ ). Estos registros estarían a disposición de la inspección municipal o policial, y de los interesados que desearan encontrar servicio o 
instituciones que proporcionaban servicio doméstico -como sociedades filantrópicas, sindicatos obreros, cooperativas obreras- y estipulaba la creación de una mutual ${ }^{85}$.

Sin lugar a dudas, este concejal demostró ser el más idóneo en el tema. Su posición era que las agencias debían seguir existiendo pero sometidas a una efectiva reglamentación. No negaba que era mucho más lo que podía argumentarse en su contra, antes que en su favor. Sin embargo, comprendía que poderosas causas debían existir para que, hasta el presente, esas casas siguieran en pie, a pesar de los ataques que les habían dirigido los sindicatos obreros (que habían luchado por su total supresión) y las autoridades públicas que, en otros contextos nacionales, habían intentado -sin éxito- prohibirlas.

Discrepó con la propuesta de Monsegur de crear oficinas municipales de colocación y de prohibir las agencias particulares. Argumentó su posición señalando que, de avanzar en esa línea, agregarían una nueva pieza al ya complicado mecanismo municipal, recargarían el presupuesto y favorecerían la "empleomanía". Además, agregó que había que reconocer que nunca un empleo municipal (a sueldo fijo, horas fijas y con muchos feriados) haría más de lo que harían aquellos que tenían un interés directo en el asunto. En cambio, consideraba que apropiadas eran las cámaras de trabajo, dirigidas por los sindicatos de obreros, donde se manifestaba un "honesto interés" por procurar un buen trabajo con el menor dispendio posible. De allí que, en vez de obstaculizarlas, bien podría la municipalidad subvencionarlas.

A su vez, a contrapelo de todos los planteos previos, aclaraba que estas disposiciones no debían herir ninguna clase de sentimientos, ni lastimar "con misteriosos registros de antecedentes" (que juzgaba "de dudosa practicabilidad, sinceridad y veracidad") la dignidad de las personas que era "tanto más respetable cuanto más humilde".

El concejal Aguilar fue el único que, dentro de su esfera de influencia, defendió a los sirvientes, haciéndose eco del clima de reforma social y de las demandas de protección del trabajo que habían comenzado a gestarse unos años atrás. Destacó que había muchos que

colocación. A su vez, entregarían a cada sirviente una "boleta", en la cual se harían constar los mismos datos que aparecían en el libro de registro correspondiente. Por último, regularía los precios máximos que podrían cobrar por sus servicios (1 peso a los sirvientes y 2 pesos a los patrones). Dictaminaba que las cuotas serían cobradas al patrón a la semana de haber aceptado al sirviente y luego éste se lo descontaría de su sueldo. El plazo era de una semana porque hasta entonces el patrón podría tomar a prueba a diferentes postulantes al servicio. Por otra parte, para denunciar el incumplimiento de la ordenanza, había que dirigirse a la "Inspección General" de la municipalidad, donde los "inspectores de servicio doméstico" atenderían la queja dentro de las primeras 48 horas.

${ }^{85}$ Estas instituciones no recibirían ayuda por parte de la municipalidad (subsidios, exenciones impositivas, etc.) si no incorporaban el uso de los registros, y en la forma establecida por las disposiciones anteriores. En el caso de la mutual, la comisión directiva estaría conformada por un concejal, dos miembros del Banco municipal de préstamos (que guardaría sus fondos), un vecino de "reconocida honorabilidad" designado por el intendente municipal y un representante de una sociedad gremial del servicio doméstico (que tuviera personería jurídica y, como mínimo, quinientos afiliados). Dicha comisión confeccionaría la reglamentación que le daría forma a ese mutualismo, para luego ser sometida a consideración y sanción en el Concejo Deliberante. 
eran víctimas de malos patrones y que, por tanto, éstos también deberían en tal caso estar sometidos a cierto registro y control ("icuán cierto es que, a menudo, no se tiene sino el servicio que se merece!", exclamó).

A su entender, las autoridades públicas tenían el deber de velar por aquellos que "eran servidos" pero así también por quienes "prestaban servicios". Intentando equilibrar un poco la representación de las partes, sostenía que había que dispensar los medios para facilitar que, aquellos que necesitaran servicio, pudieran encontrarlo "pronto y bueno" y que quienes necesitaran colocarse, a su vez, quedaran satisfechos - sin haber sido antes esquilmados.

Por otra parte, insistía en la necesidad de dejar "libradas al criterio del trato mutuo" las condiciones que hacían que un sirviente congeniara más con un patrón que con otro, porque las consecuencias de forzar esos vínculos eran por todos conocidas e iban "desde la simple separación hasta el robo y el homicidio". Para este concejal, los actos delictivos que cometían los sirvientes eran, en cierta medida, el resultado de conflictos que surgían de esas relaciones de trabajo. Al alejarse de aquella perspectiva que planteaba que los delitos perpetrados eran consecuencia de la infiltración de "elementos malsanos" en el gremio, ya que los (¿verdaderos?) sirvientes eran "honestos y leales", posibilitaba avanzar en la problematización de esas relaciones e identificar que detrás de esa "esencia" que les atribuían, lo que subyacía era aquello que los patrones consideraban que los sirvientes debían ser.

Para finalizar, es necesario aclarar que ninguna de las propuestas mencionadas tuvo éxito, ya que los proyectos una vez presentados no volvieron a ser considerados. Las disposiciones sancionadas en 1908 siguieron vigentes al menos hasta la década de 1920. La única modificación, que sufrió en 1913 la reglamentación, estuvo orientada a perfeccionar el registro de los sirvientes que por intermedio de las agencias obtenían colocación, y a reforzar los procesos para su identificación y control.

\section{A modo de cierre}

Este artículo analizó una serie de intentos de reglamentación del servicio doméstico en la ciudad de Buenos Aires a fines del siglo XIX y principios del siglo XX. El poder municipal se propuso avanzar en la regulación de las relaciones entre patrones y sirvientes y, sobre todo, someter a estos últimos a un sistemático control para garantizar un flujo de trabajadores honestos y leales para el servicio de las familias porteñas. Salvo rarísimas excepciones, lo que surge de las fuentes consultadas es que las autoridades públicas locales presentaron a los patrones como los únicos que podían ser damnificados en este tipo de vínculos, que surgían de la prestación de servicios domésticos.

A lo largo de este recorrido intenté reponer algunos elementos o dimensiones de aquella realidad social, que permiten explicar las características que asumió el tratamiento del 


\section{Revista Historia y Justicia}

ISSN 0719-4153 revista.historiayjusticia.org

Nº6 - Santiago de Chile, abril 2016, p. 103-136

servicio doméstico por parte de la administración municipal, pero también la incidencia que tuvieron los propios sirvientes en esas experiencias. Desde el punto de vista analítico pueden identificarse dos momentos diferentes, entre los que se visualizan a su vez una serie de rupturas y continuidades.

En un primer momento, en torno a las décadas de 1870 y 1880 se observan una serie de estrategias con las que los sirvientes (y aquellos que no querían ser considerados como tales) enfrentaron las restricciones normativas que la municipalidad intentó poner en práctica. En esa coyuntura, hubo tensiones que surgieron de percepciones encontradas sobre esas regulaciones y respecto a quiénes debían alcanzar. Las acciones antepuestas por los sujetos afectados adoptaron la forma de expresiones públicas y colectivas de rechazo.

Esas primeras tentativas reglamentarias no llegaron a buen puerto. El fracaso en su implementación pudo responder a varias cuestiones. Por un lado, un problema presupuestario que impidió contar con los recursos necesarios para su puesta en práctica (lo que nos habla del desinterés o de la debilidad del poder municipal para intervenir en este aspecto de la vida social). También pudo tratarse de una ordenanza difícil de aplicar por ser muy detallista y, sobre todo, por considerarse una intromisión en el dominio de lo privado: la casa, el hogar, la familia.

El otro elemento a tomar en cuenta es la resistencia de aquellos que fueron objeto de dicha intervención. Los patrones objetaron que se atentaba contra la libertad para contratar sobre todo cuando se establecía la prohibición de emplear sirvientes sin registro o certificación-, y que se trataba de disposiciones coactivas (por las elevadas penalizaciones que instituía). Además, podían generar rigideces con los sirvientes, sobre todo con los que llevaban largo tiempo junto a ellos. Del lado de los sirvientes, la medida fue recibida como un atentado a la libertad de trabajo, y también lo que se observa es una negativa a someterse a esas formas de vigilancia y control, por resultar cada vez más estigmatizantes. A esto se le suma el rechazo por parte de algunos gremios a ser asimilados -y tratados- como sirvientes, por considerarlo perjudicial y ofensivo para su "dignidad profesional".

Esto último remite a otros aspectos de los efectos de la reglamentación, que son de orden simbólico. Hablan de la poca consideración que tenían los sirvientes en la sociedad porteña, no sólo por parte de los patrones, sino también entre los mismos trabajadores. Además, permiten pensar las tensiones y diferencias en relación a los sentidos y las concepciones que los representantes del poder municipal, los patrones y los trabajadores adjudicaron al universo de los servicios domésticos en general, y a la expresión "sirvientes" en particular.

Con el cambio de siglo es posible identificar un segundo momento. En el marco de la emergencia de la denominada "cuestión social", donde la intensificación de la conflictividad social y la irrupción de nuevas formas de protesta son por demás palpables, aparece una primera experiencia gremial: la Liga Internacional de Domésticos. Se trató de una sociedad de 
resistencia de raigambre socialista que intentó organizar a los domésticos para mejorar sus condiciones de vida y de trabajo.

A pesar de los bajos niveles de agremiación y del poco influjo que pudo haber tenido, es una experiencia que merece ser atendida porque colocó en el centro de la escena una problemática que resultó ser el principal foco de las intervenciones públicas posteriores: el funcionamiento de las agencias de colocación particulares. Desde su creación, la Liga batalló contra estas casas, confeccionando petitorios, juntando firmas, organizando meetings, publicando artículos, con el objetivo de que las autoridades públicas prohibieran las agencias o, al menos, controlaran de forma más efectiva una operatoria que resultaba escandalosa. El DNT también atendió a este fenómeno y contribuyó a visibilizarlo e instalarlo como problema en la agenda pública. Este organismo confeccionó datos y ofreció informaciones sobre estas casas desde un primer momento, y registró sus irregularidades e intervino de forma concreta para que el poder municipal reforzara los controles sobre las mismas.

Es difícil mensurar el influjo que tuvieron estos dos actores en la decisión de las autoridades locales de avanzar (una vez más) en la regulación del servicio doméstico. En realidad, viejas y nuevas motivaciones parecen haberse entrelazado en los proyectos reglamentarios que surgen en torno a 1910. Por un lado estaba el mencionado interés de las organizaciones obreras, y de dicho organismo, en que la municipalidad regulara las agencias para salvaguardar a los y las trabajadoras de la voracidad y ambición de esas casas que los esquilmaban. Por otro lado estaban las preocupaciones que el servicio doméstico generaba entre los patrones -sobre todo, en lo que a su seguridad e integridad física y material respecta-, cuando introducían en su hogar a una persona extraña.

Si en general aparece una voluntad reglamentaria focalizada en las agencias, una mirada más detallada del contenido de los proyectos permite observar que no recogieron la perspectiva "de los trabajadores", y que lejos estuvieron de asumir una posición en favor de ambas partes, patrones y sirvientes (a excepción del proyecto de Aguilar). Lo que apremiaba para las autoridades municipales era la adopción de medidas que resguardasen al patrón. A pesar del paso del tiempo, los ediles plantearon el problema de la regulación del servicio doméstico en los mismos términos: cómo garantizar un flujo de sirvientes honestos y decentes que no resultaran una amenaza para quienes los tomaban.

Si bien reclamar iniciativas en favor de los sirvientes resultaría descabellado en la década de 1870, para 1910 el contexto era distinto. Pero la emergencia del "derecho del trabajo", y el impulso de proyectos en beneficio de distintos grupos y sectores laborales, que obtuvieron fuerza de ley desde principios de siglo, no hicieron eco en el tratamiento del sector. Aunque desde algunos frentes se reclamaron reglamentaciones que resguardaran a los domésticos en tanto que trabajadores, resulta evidente que el poder municipal se abocó a resguardar fundamentalmente a los patrones. 
La discusión sobre la regulación del servicio doméstico giró en torno a las agencias de colocación, la conveniencia de su existencia o de su prohibición, y el carácter público o privado que ellas debían tener. En relación a este último punto, los concejales acordaban que, al perseguir el lucro (a más colocaciones, más comisiones), las agencias no daban garantías ni seguridades a los patrones respecto de las condiciones de moralidad y competencia que debía tener el servicio que recomendaban.

Frente a este panorama, estaban quienes pretendían seguir reglamentando su funcionamiento sometiéndolas a un control más efectivo. Pero también estaban quienes querían prohibirlas y reemplazarlas por dependencias municipales o por bolsas de trabajo bajo el control de los sindicatos, que brindarían el servicio de intermediar entre la oferta y la demanda para evitar las estafas y chantajes de los que eran víctimas, patrones y sirvientes, pero por sobre todas las cosas, para garantizar el suministro de sirvientes honrados y confiables a las familias porteñas.

Evidentemente, una vez más, lo que primó fue la necesidad de calmar las ansiedades de los patrones. La permanente referencia a sirvientes en la crónica policial, su frecuente extranjería y la imposibilidad de conocer su pasado, aumentaron la urgencia de implementar nuevos controles para intentar reducir la posibilidad de ser víctimas de actos criminales. El servicio doméstico habilitaba esa posibilidad ya que en el seno de las familias convivían individuos de mundos disímiles pero concurrentes, que participaban de relaciones e interacciones de contigüidad y exterioridad, que daban lugar, en ocasiones, a intromisiones escurridizas y desplazamientos "indeseables" que afectaron el orden urbano. Sólo considerando esos aspectos inquietantes, que las transformaciones de la ciudad habían generado, es que se puede comprender mejor la naturaleza de las regulaciones del servicio doméstico en torno al Centenario.

\section{Fuentes}

Biblioteca Nacional Mariano Moreno

-Caras y Caretas (1898-1915).

-La Vanguardia (1900-1925).

-Revista de policía (1918).

-Código Civil de la República Argentina, Buenos Aires, Pablo E. Coni, 1874.

Biblioteca Tornquist

-Boletín del Departamento Nacional del Trabajo, varios números, ediciones y años (1907-1915).

Dirección General Centro Documental de Información y Centro Legislativo

- Actas de la Comisión Municipal de la Ciudad de Buenos Aires correspondiente al año 1875, Publicación ordenada por el Presidente del H. Concejo Deliberante Dr. Carlos M Coll, Buenos Aires, Talleres Gráficos “Optimus”, 1912. 


\section{Revista Historia y Justicia}

ISSN 0719-4153 revista.historiayjusticia.org

Nº6 - Santiago de Chile, abril 2016, p. 103-136

-Decreto Reglamentario del Estatuto del Servicio Doméstico, Boletín Oficial, 30 de abril de 1956.

-Digesto Municipal de la Ciudad de Buenos Aires. Recopilación de leyes, ordenanzas y decretos, varios recopiladores, ediciones y años (1877-1918).

-Memoria del Presidente de la Comisión Municipal al Concejo correspondiente al ejercicio de 1879, Tomo primero, Buenos Aires, Imprenta de Martín Biedma, 1880.

-Versiones Taquigráficas de las Sesiones del H. Concejo Deliberante de la Ciudad de Buenos Aires, varios períodos, ediciones y años (1900-1912).

Biblioteca del Ministerio de Trabajo, Empleo y Seguridad Social, República Argentina

-Boletin del Departamento Nacional del Trabajo.

\section{Bibliografía}

Allemandi, Cecilia L., "Niños Sirvientes y 'criados': el trabajo infantil en el servicio doméstico (ciudad de Buenos Aires, fines del siglo XIX-principios del siglo XX)", en Cuadernos del IDES, n⿳30, ISSN 1668-1053, Octubre de 2015, p. 11-38, http://ides.org.ar/wpcontent/uploads/2012/03/Cuadernos-del-

IDES-N\%C2\%BA-30-Octubre-2015.pdf.

"Las amas de leche y la regulación del mercado de la lactancia en la ciudad de buenos Aires (1875-1911)", en Revista Mora, ISSN 1853001X (en prensa).

Armus, Diego, "El descubrimiento de la enfermedad como problema social", en Lobato, Mirta Zaida (dir.), Nueva Historia Argentina. El progreso, la modernización y sus límites (1880-1916), Tomo 5, Editorial Sudamericana, Buenos Aires, 2000.

Birgin, Haydée, "Sin acceso a la justicia: el caso de las trabajadoras domésticas en la Argentina", en Valenzuela, María Elena \& Mora, Claudia (eds.), Trabajo doméstico: un largo camino hacia el trabajo decente, OIT, Santiago de Chile, 2009.

Caimari, Lila, Apenas un delincuente. Crimen, castigo y cultura en la Argentina, 1880-1955, Siglo XXI Editores Argentina, Buenos Aires, 2004, p. 75-85.

Chaney Elsa, García Castro Mary (eds.), Muchacha, cachifa, criada, empleada, empregadinba, sirvienta y más nada, 1ra edición en español, Nueva sociedad, Caracas, 1993.

Devoto, Fernando, Historia de la inmigración en la Argentina, Sudamericana, Buenos Aires, 2009.

García Ferrari, Mercedes, “ 'Una marca peor que el fuego'. Los cocheros de la Ciudad de Buenos Aires y la resistencia al retrato de identificación", en Lila Caimari (comp.), La ley de los profanos. Delito, justicia y cultura en Buenos Aires (1880-1940), Fondo de Cultura Económica, Buenos Aires, 2007.

Ladrones Conocidos / Sospechosos reservados. Identificación policial en Buenos Aires, 18801915, Prometeo Libros, Buenos Aires, 2010.

Falcón, Ricardo, El mundo del trabajo urbano (18901914), CEAL, Buenos Aires, 1986.

González, Ricardo, Gente y Sociedad. Los obreros y el trabajo. Buenos Aires, 1901, CEAL, Buenos Aires, 1984.

Guy, Donna J., El sexo peligroso: la prostitución legal en Buenos Aires, 1895-1955, Sudamericana, Buenos Aires, 1994.

Iscaron, Rubens, Historia del movimiento sindical, Editorial Ciencias del Hombre, Buenos Aires, 1974.

Korn, Francis, Buenos Aires 1895. Una ciudad moderna, Editorial del Instituto, Buenos Aires, 1981. 
Liernur, Jorge Francisco "La ciudad efímera, consideraciones sobre el aspecto material de Buenos Aires, 1870-1910", en Liernur, Jorge F. \& Silvestre, Graciela, El umbral de la metrópolis. Transformaciones técnicas y cultura en la modernización de Buenos Aires (1870-1930), Editorial Sudamericana, Buenos Aires, 1993.

"La construcción del país urbano", en Lobato, Mirta Z. (dir.), Nueva Historia Argentina. El progreso, la modernización y sus límites (1880-1916), Tomo 5, Editorial Sudamericana, Buenos Aires, 2000.

Lobato, Mirta Z., "Los trabajadores en la era del progreso", en Lobato, Mirta Z. (dir.), Nueva Historia Argentina. El progreso, la modernización y sus limites (1880- 1916), Tomo 5, Editorial Sudamericana, Buenos Aires, 2000.

Marotta, Sebastián, El movimiento sindical argentino. Su génesis y desarrollo, Tomo I, Período 1857-1907, Ediciones Lacio, Buenos Aires, 1960.

Oficina Internacional del Trabajo, Trabajo decente para los trabajadores domésticos, OIT, Ginebra, 2009.

Panettieri, José, Las primeras leyes obreras, CEAL, Buenos Aires, 1984.

Pereira, Milena \& Valiente, Hugo, Regimenes jurídicos sobre trabajo doméstico remunerado en los Estados del MERCOSUR, Cotidiano Mujer, Montevideo, disponible en: http://www.cotidianomujer.org.uy/regimenes_es p2010.pdf.

Recchini de Lattes, Zulma, "Crecimiento explosivo y desaceleración", en J. L. Romero \& L. A. Romero (Dirs.), Buenos Aires. Historia de cuatro siglos, Tomo II, Altamira, Buenos Aires, 1983.

Sábato, Hilda \& Romero, Luis Alberto, Los trabajadores de Buenos Aires. La experiencia del mercado, 1850-1880, Sudamericana, Buenos Aires 1992.

Scobie, James R., Buenos Aires. Del centro a los barrios, 1870-1910, Solar/Hachette, Buenos Aires, 1977.

Stagnaro, Andrés, Los tribunales de trabajo como el escenario del conflicto entre el capital y el trabajo. 19481960, Tesis de Doctorado en Historia, Universidad Nacional de La Plata, La Plata, 2012.

Suriano, Juan, "La oposición anarquista a la intervención estatal en las relaciones laborales", en Suriano, Juan (comp.), La cuestión social en Argentina 1870- 1943, La colmena, Buenos Aires, 2000.

Tizziani, Ania, "El Estatuto del Servicio Doméstico y sus antecedentes: debates en torno a la regulación del trabajo doméstico remunerado en la Argentina", en Nuevo Mundo Mundos Nuevos, $\mathrm{n}^{\circ} 13,2013, \quad$ disponible en http://nuevomundo.revues.org/65153.

Valenzuela, María Elena, "Esfuerzos concertados para la revaloración del trabajo doméstico remunerado en América Latina", en Valenzuela, María Elena \& Mora, Claudia (eds.), Trabajo doméstico: un largo camino hacia el trabajo decente, OIT, Santiago de Chile, 2009.

Zimmermann, Eduardo A., Los liberales reformistas. La cuestión social en la Argentina 1890-1916, Sudamericana-Universidad de San Andrés, Buenos Aires, 1995.

"La sociedad entre 1870 y 1914", en Academia Nacional de la Historia, Nueva Historia de la Nación Argentina, Tomo IV, Tercera Parte, La configuración de la República independiente 1810c.1914, Editorial Planeta, Buenos Aires, 2000. 